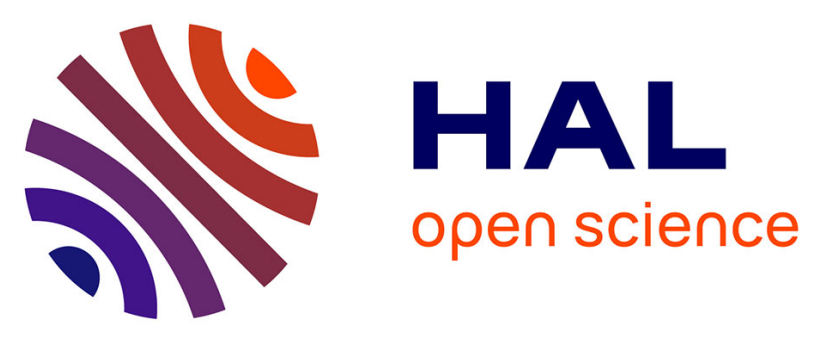

\title{
TRP channel-associated factors are a novel protein family that regulates TRPM8 trafficking and activity
} Dimitra Gkika, Loic Lemonnier, George Shapovalov, Dmitri Gordienko, Céline Poux, Michela Bernardini, Alexandre Bokhobza, Gabriel Bidaux, Cindy Degerny, Kathye Verreman, et al.

\section{To cite this version:}

Dimitra Gkika, Loic Lemonnier, George Shapovalov, Dmitri Gordienko, Céline Poux, et al.. TRP channel-associated factors are a novel protein family that regulates TRPM8 trafficking and activity. Journal of Cell Biology, 2015, 208 (1), pp.89-107. 10.1083/jcb.201402076 . hal-01111024

\author{
HAL Id: hal-01111024 \\ https://hal.science/hal-01111024
}

Submitted on 4 Dec 2019

HAL is a multi-disciplinary open access archive for the deposit and dissemination of scientific research documents, whether they are published or not. The documents may come from teaching and research institutions in France or abroad, or from public or private research centers.
L'archive ouverte pluridisciplinaire HAL, est destinée au dépôt et à la diffusion de documents scientifiques de niveau recherche, publiés ou non, émanant des établissements d'enseignement et de recherche français ou étrangers, des laboratoires publics ou privés.

\section{(1)(1) $\$(0)$}

Distributed under a Creative Commons Attribution - NonCommercial - ShareAlikel 4.0 


\title{
TRP channel-associated factors are a novel protein family that regulates TRPM8 trafficking and activity
}

\author{
Dimitra Gkika, ${ }^{1}$ Loic Lemonnier, ${ }^{1}$ George Shapovalov, ${ }^{1}$ Dmitri Gordienko, ${ }^{1}$ Céline Poux, ${ }^{2}$ Michela Bernardini, ${ }^{1,6}$ \\ Alexandre Bokhobza, ${ }^{1}$ Gabriel Bidaux, ${ }^{3}$ Cindy Degerny, ${ }^{4}$ Kathye Verreman, ${ }^{4}$ Basma Guarmit, ${ }^{5}$ Mohamed Benahmed, ${ }^{5}$ \\ Yvan de Launoit, ${ }^{4}$ Rene J.M. Bindels, ${ }^{7}$ Alessandra Fiorio Pla, ${ }^{1,6}$ and Natalia Prevarskaya ${ }^{1}$ \\ 'Inserm U 1003, Equipe labellisée par la Ligue Nationale Contre le Cancer, Université des Sciences et Technologies de Lille (USTL), 59655 Villeneuve d'Asca Cedex, France \\ ${ }^{2}$ Centre national de la Recherche Scientifique (CNRS) UMR 8198 and Laboratoire de Génétique \& Evolution des Populations Végétales (GEPV), Université des Sciences et \\ Technologies de Lille (USTL), 59655 Villeneuve d'Asca Cedex, France \\ ${ }^{3}$ Laboratoire Biophotonique Cellulaire Fonctionnelle, Institut de Recherche Interdisciplinaire, USR3078 Centre National de la Recherche Scientifique, Parc scientifique de la \\ Haute Borne, Villeneuve d'Ascq, F-59655 France \\ ${ }^{4}$ CNRS UMR 8161 , Institut de Biologie de Lille, Université de Lille-Nord de France, Institut Pasteur de Lille, 59019 Lille Cedex, France \\ ${ }^{5}$ Inserm, Institut National de la Santé et de la Recherche Médicale U895, Centre Méditerranéen de Médecine Moléculaire, Hôpitall'Archet, O6204 Nice, France \\ ${ }^{6}$ Department of Life Science and Systems Biology, University of Torino, 10123 Torino, Italy \\ ${ }^{7}$ Department of Physiology, Radboud University Nijmegen Medical Centre, 6500HB Nijmegen, Netherlands
}

$\mathrm{T}$ RPM8 is a cold sensor that is highly expressed in the prostate as well as in other non-temperaturesensing organs, and is regulated by downstream receptor-activated signaling pathways. However, little is known about the intracellular proteins necessary for channel function. Here, we identify two previously unknown proteins, which we have named "TRP channel-associated factors" (TCAFs), as new TRPM8 partner proteins, and we demonstrate that they are necessary for channel function. TCAF1 and TCAF2 both bind to the TRPM8 channel and promote its trafficking to the cell surface. However, they exert opposing effects on TRPM8 gating properties. Functional interaction of TCAF1/TRPM8 also leads to a reduction in both the speed and directionality of migration of prostate cancer cells, which is consistent with an observed loss of expression of TCAF1 in metastatic human specimens, whereas TCAF2 promotes migration. The identification of TCAFs introduces a novel mechanism for modulation of TRPM8 channel activity.

\section{Introduction}

Transient receptor potential (TRP) channels form a large family of cation channels involved in a diverse range of physiological functions, and are expressed in almost all cell types (Clapham, 2003). They play important roles ranging from $\mathrm{Ca}^{2+}$ absorption, vasorelaxation, cell death, mechanotransduction, and hearing, to the mediation of $\mathrm{pH}$, heat, taste, osmolarity, and pain sensations. Dysfunctions of TRP channels have been linked to several diseases (Nilius et al., 2007). Among members of the TRP channel family, the function of TRPM 8 could be considered one

D. Gkika, L. Lemonnier, and G. Shapovalov contributed equally to this paper. Correspondence to Dimitra Gkika: dimitra.gkika@univ-lille1.fr

D. Gordienko's present address is Laboratory of Molecular Pharmacology and Biophysics of Cell Signalling, Bogomoletz Institute of Physiology, State Key Laboratory of Molecular and Cell Biology, $01024 \mathrm{Kiev}$, Ukraine.

Abbreviations used in this paper: EAPA2, Experimental Autoimmune Prostatitis Antigen 2; FRET, Förster resonance energy transfer; HEK, human embryonic kidney; LNCaP, lymph node carcinoma of prostate; ML, maximum likelihood method; qPCR, quantitative real-time PCR; TCAF, TRP channel-associated factor; TCSPC, time-correlated single photon counting; TD FLIM, time-domain fluorescence lifetime imaging microscopy; TRP, transient receptor potential. of the most intriguing. Although it was initially cloned from the prostate (Tsavaler et al., 2001; Stein et al., 2004) and is expressed in tissues not affected by ambient temperature fluctuations such as the prostate, testis, and bladder (Tsavaler et al., 2001; Stein et al., 2004), this channel is mainly known as the principal detector of environmental cold (Bautista et al., 2007; Colburn et al., 2007; Dhaka et al., 2007).

TRPM8 expression is strongly up-regulated in numerous cancers such as that of the prostate, but is dramatically reduced during metastasis in androgen-independent prostate cancers (Tsavaler et al., 2001; Henshall et al., 2003; Yee et al., 2010). This pattern of variation of TRPM8 expression makes it an interesting candidate both as a diagnostic marker for the detection of certain cancers and as a prognostic marker in evaluating the

(C) 2015 Gkika et al. This article is distributed under the terms of an Attribution-NoncommercialShare Alike-No Mirror Sites license for the first six months after the publication date (see http://www.rupress.org/terms). After six months it is available under a Creative Commons License (Attribution-Noncommercial-Share Alike 3.0 Unported license, as described at http://creativecommons.org/licenses/by-nc-sa/3.0//. 
outcome of these cancers (Zhang and Barritt, 2006). In addition, it could play a protective role in metastatic prostate cancer (Gkika and Prevarskaya, 2011), as recent data show that it blocks the migration of prostate cancer cells (Yang et al., 2009; Gkika et al., 2010; Zhu et al., 2011). Thus, although TRPM8 is considered to be a promising target for pharmaceutical, immunological, and genetic interventions for the treatment of prostate cancer (Zhang and Barritt, 2006), it is first necessary to better understand its biological function and the physiological modulators in this organ.

Besides cool temperatures, TRPM8 is also activated by several chemical compounds that elicit a sensation of cold, of which the best known are menthol, eucalyptol, and the supercooling icilin (McKemy et al., 2002; Peier et al., 2002; Behrendt et al., 2004; Chuang et al., 2004; Beck et al., 2007; Bödding et al., 2007). Chemical agents generally serve as positive allosteric modulators. More specifically, because the activation of TRPM8 is also voltage dependent, these agonists shift the activation threshold toward more negative potentials, enabling the channel to open at higher than normal temperatures, whereas antagonists exert their effect by shifting the threshold of TRPM8 activation toward more positive potentials (Brauchi et al., 2004; Voets et al., 2004; Mälkiä et al., 2007).

In the absence of the aforementioned physical and chemical stimuli, as could be the case in non-temperaturesensing tissues, TRPM8 could be kept in readiness in a dynamic pool of vesicles under the cell surface, awaiting the appropriate signal for plasma membrane insertion and channel activation (Veliz et al., 2010; Latorre et al., 2011). This dynamic TRPM8 pool could be activated by intracellular factors known to modulate TRPM8 activity, such as second messengers generated during the activation of surface-receptorcoupled signaling pathways (Bavencoffe et al., 2010, 2011; Latorre et al., 2011; Yudin and Rohacs, 2012; Zhang et al., 2012; Shapovalov et al., 2013a). However, the intracellular elements involved in controlling the stabilization of the channel on the cell surface and the subsequent amplification of its activity are currently unknown.

Several studies show that TRP channels can be regulated by partner proteins affecting their trafficking to the plasma membrane (Vogel et al., 2007) and/or their channel activity (van de Graaf et al., 2003, 2006; Gkika et al., 2004, 2006a,b; Sinkins et al., 2004; Chang et al., 2005; Köttgen and Walz, 2005). Indeed, the regulated translocation of TRP channels appears to be a key mechanism for the gating of constitutively active subunits, as well as for enhancing the activity of stimulus-gated channels (Shapovalov et al., 2013a). Thus, the identification of the molecular components implicated in this cellular process is of great importance in understanding not only the regulatory mechanisms of TRP channels but also their function.

To identify and characterize the molecular determinants of TRPM8 regulation, we performed a screening for TRPM8 partner proteins in the prostate, where the channel is primarily expressed. As a result, we have identified a previously uncharacterized protein family as a first example of TRPM8 regulators.

\section{Results}

Identification of the TRP channel-associated factors (TCAFs): a family of TRPMB partner proteins

To identify TRPM8 regulatory proteins, which have not been identified until now, we performed a GST pull-down assay to screen lysates of healthy mouse prostates, with the N-terminal and C-terminal cytosolic tails of TRPM8 as bait. Fourier transform ion cyclotron resonance mass spectrometry (FTMS) revealed mouse Experimental Autoimmune Prostatitis Antigen 2 (EAPA2) as a protein interacting with TRPM8. The full list of peptides interacting with TRPM8 cytosolic tails is presented in Tables S1 and S2. As EAPA2 is not known in humans, we searched for highly homologous proteins using National Center for Biotechnology Information (NCBI) Blast. Two proteins of unknown function, FAM115A, consisting of 921 amino acids (NP_055534), and FAM115C, consisting of 845 amino acids (NP_001123497), were thus identified and named TCAF1 and -2. The alignment of these two proteins with EAPA2 (hereafter renamed TCAF3) revealed $51 \%$ and $57 \%$ of identity, respectively. Once substitutions by similar residues were taken into account, the similarity between TCAF3 and TCAF1 or TCAF2 reached $69 \%$ and $66 \%$, respectively (see Fig. 2), which suggests that they may have a common origin and belong to the same group of genes.

Indeed, a phylogenetic analysis of TCAF1, TCAF2, and TCAF3 revealed the presence of a putative gene family. Given the sequences available in GenBank, we determined two duplication events (Fig. 1 A), supported by both posterior probabilities (PP; Bayesian method) and bootstrap supports (BP; maximum likelihood method [ML]). In mammals, up to three highly similar genes were found (TCAF1, TCAF2, and TCAF3), whereas only one gene copy was seen in fish, amphibians, and birds. The mammalian TCAF1 and TCAF2 sequences are phylogenetically closer to each other than to the other vertebrate sequences. Therefore the first duplication event most likely occurred during mammalian evolution. Given the poor taxon sampling available in the database, it was not possible to precisely determine the period of duplication. A second duplication event appears to have taken place during rodent evolution to generate the TCAF3 gene (Fig. $1 \mathrm{~A}$ ).

Although mouse TCAF3 is mainly expressed in the prostate, nothing is known about the tissue distribution of the newly identified human homologues. We thus examined TCAF1 and TCAF2 expression in several human tissue samples using quantitative real-time PCR ( $\mathrm{PPCR}$ ). Both transcripts were predominantly expressed in the prostate (Fig. $1 \mathrm{~B}$ ), similar to TCAF3 in rodents and TRPM8 in humans and rodents.

Both TCAF1 and TCAF2 interact directly with the TRPMB channel

To verify the association of human TCAF1 and TCAF2 proteins with TRPM8, we cloned TCAF1 and TCAF2 and studied their interaction with TRPM8 by GST pull-down assays. In vitrotranslated $\left[{ }^{35} \mathrm{~S}\right]$ methionine-labeled TCAF1 and TCAF2 strongly interacted with the TRPM8 N-terminal tail (GST-M8N) and to 


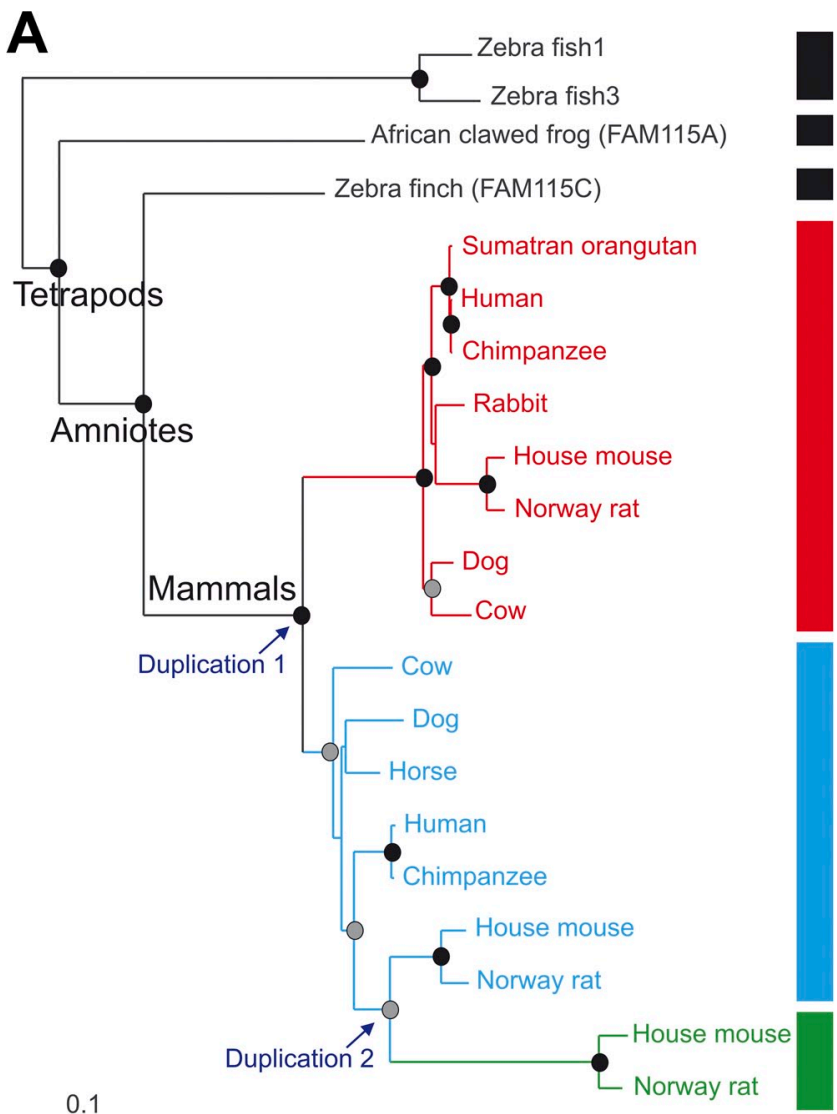

Ray-finned fishes

Amphibians Birds

Mammals

FAM115A

\section{Mammals}

FAM115C

\section{Rodents}

EAPA2
Figure 1. Bayesian phylogenetic tree of the vertebrate TCAF1/TCAF2/TCAF3 genes and tissue expression pattern of the human homologues. (A) The maximum likelihood tree was similar but for one node: the cow and horse FAM $115 \mathrm{C}$ sequences were sister groups. The phylogenetic reconstruction displays two duplication events, one during the early period of mammalian evolution and the other during rodent evolution. The scale bar represents the number of expected changes per site. (B) Analysis of TRPM8, TCAF1, and TCAF2 mRNA expression levels by qPCR in several human tissues. Values are expressed relative to $18 \mathrm{~S}$ rRNA expression, and further normalized to TRPM8 levels in the prostate. Values are presented as means of three experimental repeats \pm SEM (error bars; $n=3$ for a single experiment).

- $\mathrm{PP} \geq 0.98$ and $\mathrm{BP} \geq 85$

- $\mathrm{PP} \geq 0.98$ or $\mathrm{BP} \geq 85$

B

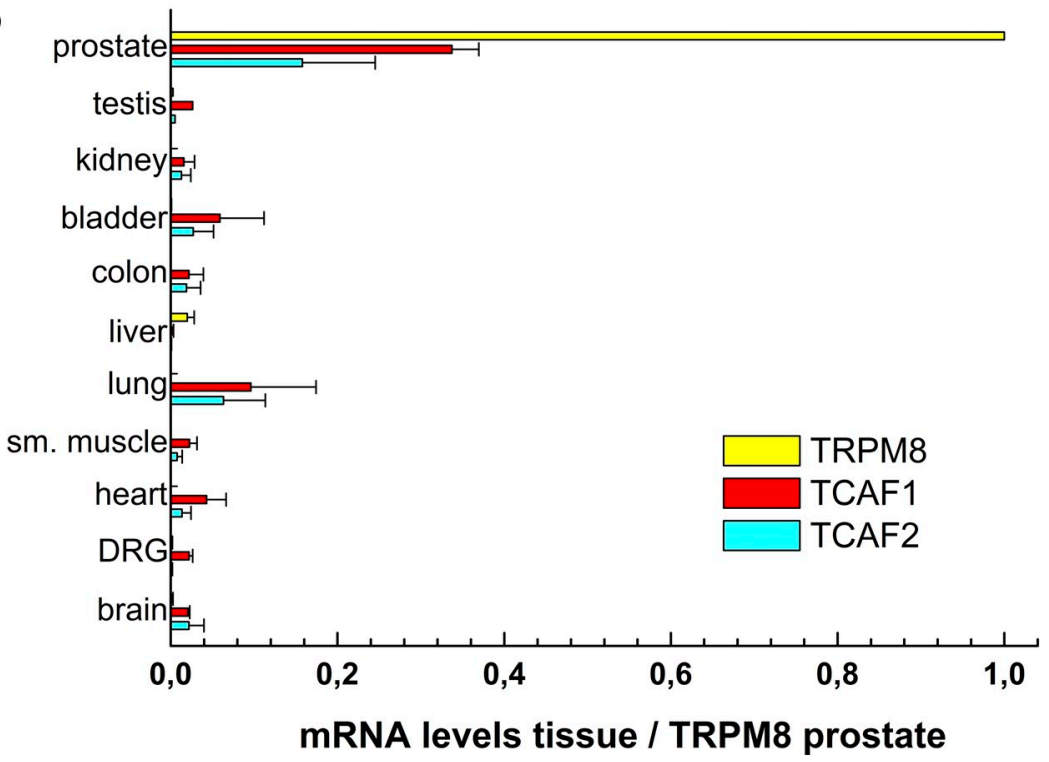

a lesser extent with the TRPM8 C-terminal tail (GST-M8C), whereas no interaction was observed with GST alone (Fig. 3 A). This interaction was further confirmed by immunoprecipitation experiments in human embryonic kidney (HEK) 293 cells transfected with either HA-tagged TCAF1 or myc-tagged TCAF2, with or without his-tagged full-length TRPM8. TRPM8 was present on the beads and was detected in the precipitated complex (IP) with TCAF1 and TCAF2. No band was detected in precipitated complexes from cells that were not transfected with TRPM8 or cells immunoblotted for another protein such as actin, which indicates the specificity of the interaction (Fig. 3 B). TCAF interactions with additional TRP channels were also analyzed 


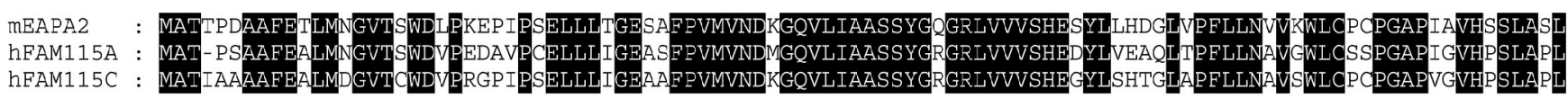

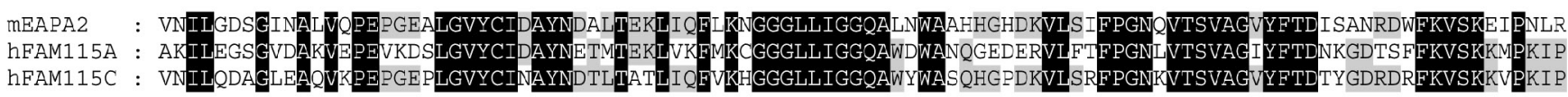

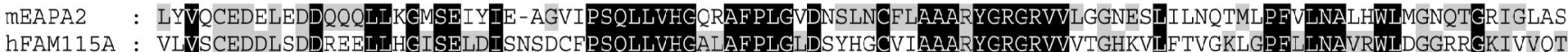

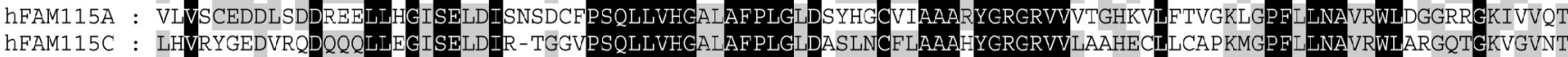

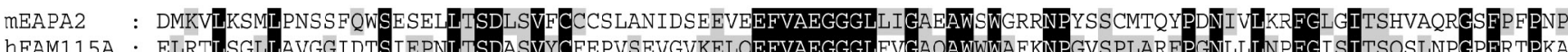

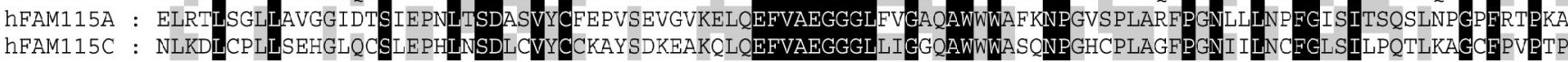

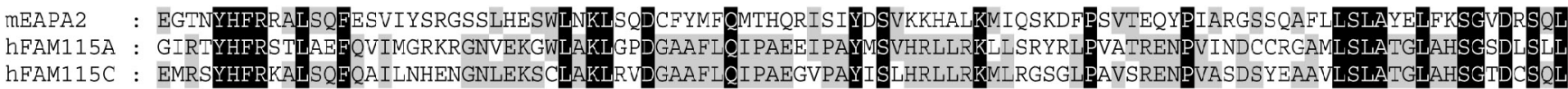

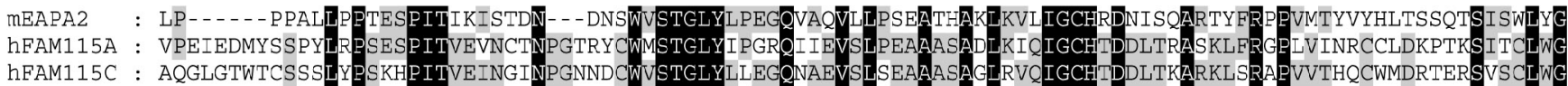

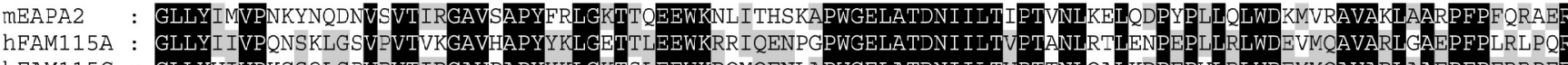
hFAM115C : GLLYVIVPKGSQLGPVPVIIRGAVPAPYYKLGKTSLEEWKRQMQENLAPWGELATDNI I LTVPTTNLQALKDPEPVLRLWDEMIMAVARLAAEPFPFRRPEA

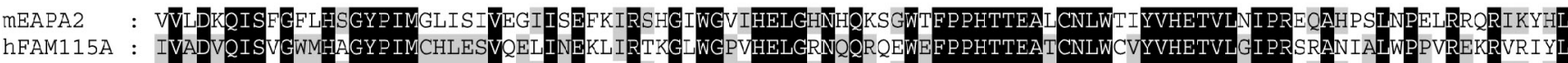
hFAM115A : IVADVQISVGWMHAGYPIMCHLESVQELINEKLIRTKGLWGPVHELGRNQQRQEWEFP PHTTEATCNLWCVYVHETVLGI PRSRANIALWPPVREKRVRIY hFAM115C : IVADVQISAGWMHSGYPIMCHLESVKEIINEMDMRSRGVWGP IHELGHNQQRHGWEFP PHTTEATCNLWSVYVHETVLGI PRAQAHEALSPPERERRI KAHI

MEAPA2 : NKKAPLSNWIMTTALETYLQLQEGFGWEPFIQVFADYRTLSGLPQNNEDKMNLWVKKFSEAVHKNLAPFFEAWGWPVKYAVAKSLASLPEWQENPMKRYT hFAM115A : SKGPNVKNWNANTALETYLQLQEAFGWEPF IRLFTEYRNQTNLPTENVDKMNLWVKMFSHQVQKNLAPFFEAWAWPIQKEVATSLAYLPEWKENIMKLYL hFAM115C : GKGAPLCDWNVWTALETYLQV

Figure 2. Human homologues of TCAF3. Alignment of hFAM115A (TCAF1) and hFAM1 15C (TCAF2) with the murine EAPA2 (TCAF3) protein. Amino acid residues are highlighted in black when present in the three proteins and in gray when they are present in only two of them.

by coimmunoprecipitation to check whether TCAF is a TRPM8exclusive partner. Altogether, these results show that TCAFs are potential partner proteins for other TRP channels, such as TRPV6 and the short isoform of TRPM2 (Fig. S1, A and B).

Confocal imaging of the cells transfected with HA-tagged TCAF1 or myc-tagged TCAF2 and labeled with TRPM8 antibodies confirmed that both TCAFs colocalize with TRPM8 (Fig. S2, A and B). Direct interaction between the two proteins in living cells was confirmed by means of Förster resonance energy transfer (FRET) using the time-domain fluorescence lifetime imaging microscopy (TD FLIM). After the 24-h transfection, HEK cells expressing TRPM8-mTurquoise 2 and TCAF-SYFP2 (Fig. $3 \mathrm{C}$ ) were analyzed using the time-correlated single photon counting (TCSPC) of the donor fluorescence (Fig. 3, $\mathrm{D}$ and $\mathrm{E}$ ), and the lifetime of mTurquoise 2 was computed on a pixel-by-pixel basis (Fig. 3, D and E). Statistical analysis revealed significant FRET between TRPM8 and TCAF1 or TCAF2 (Fig. 3 F). In control experiments on HEK cells expressing TRPM8-mTurquoise2 and free SYFP2, no significant variation of mTurquoise 2 lifetime was detected (Fig. $3 \mathrm{~F}$ ), and calculated $\mathrm{E}_{\mathrm{FRET}}$ was found to be below the confidence threshold of $1 \%$. These observations altogether with biochemical analysis of interaction confirmed in living cells that TCAFs are partners of the TRPM8 channels.

\footnotetext{
TCAFs exert opposing regulatory effects on TRPMB-mediated currents
}

To assess the functional effect of TCAF1-TCAF2 interactions with the TRPM8 channel in human prostate cells, we performed a series of patch-clamp experiments. The silencing of native TCAFs by siRNAs to TCAF1 or -2 was monitored by RT-PCR after $72 \mathrm{~h}$, and specifically abolished TCAF1 or -2 expression 
A

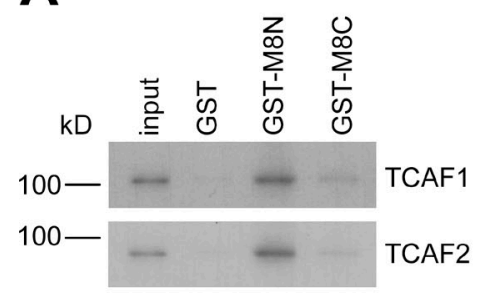

C
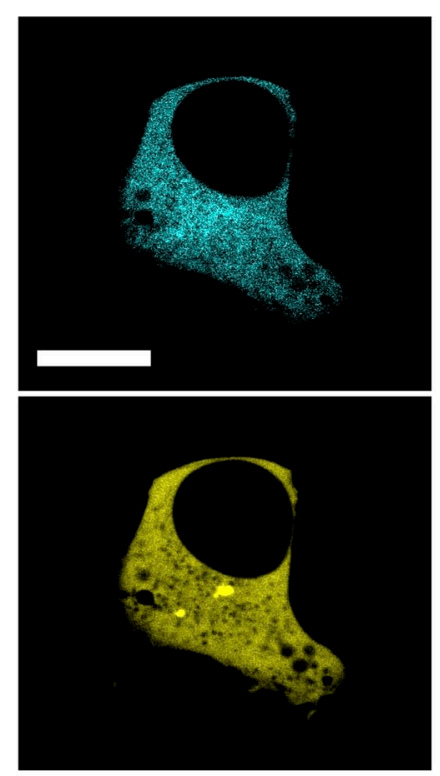

B

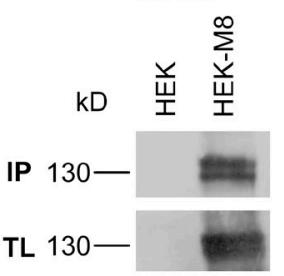

D

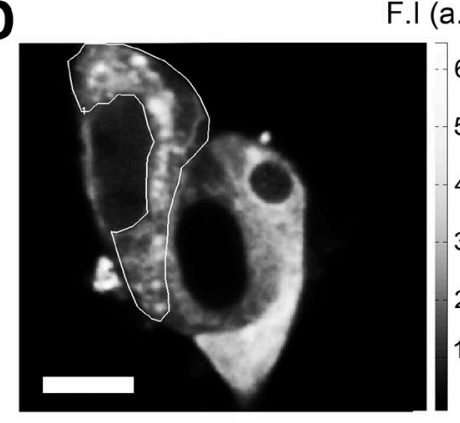

F.I (a.u.)

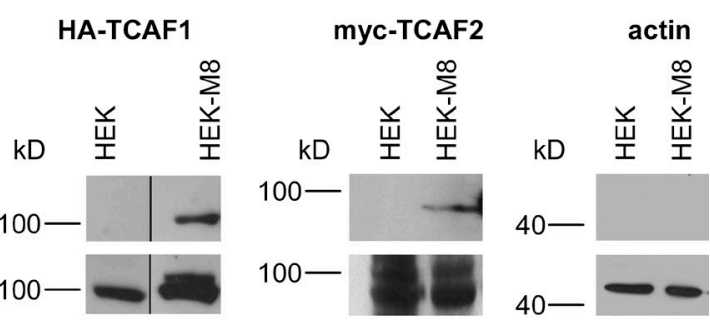

E
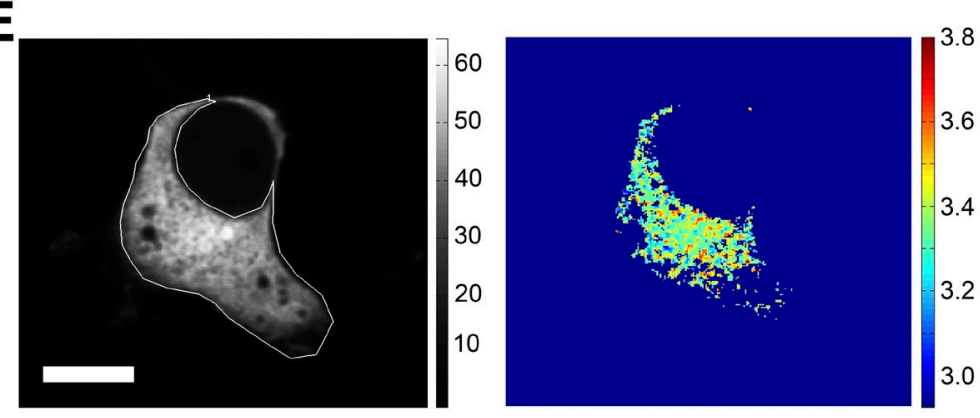

F

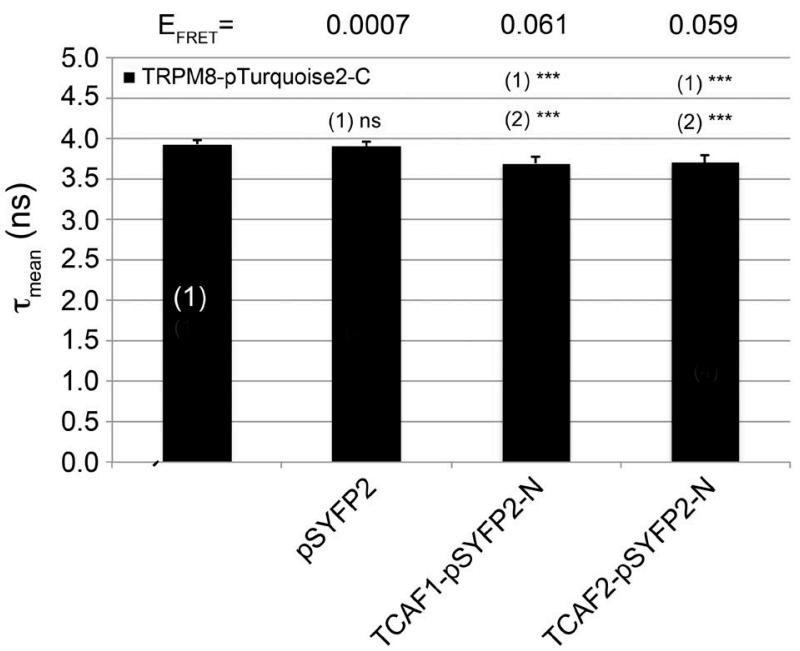

Figure 3. TCAF1 and TCAF2 interact and colocalize with TRPM8. (A) GST pull-down assay using ${ }^{35}$ S $]$ methionine-labeled TCAF 1 or TCAF2 protein and GST or GST fused to the TRPM8 N-terminal tail (GST-M8N) or C-terminal tail (GST-M8C). (B) Cells transfected with HA-tagged TCAF1 or myc-tagged TCAF2 with (HEK-M8) or without (HEK) his-tagged full-length TRPM8, and total lysates (TL) were used for immunoprecipitation and subsequent immunoblot analysis. Immunoprecipitation of the channel was confirmed by immunoblotting for TRPM8, and the coimmunoprecipitation of TCAF1 or TCAF2 proteins was detected using an anti-HA or anti-myc antibody, respectively, on the immunoprecipitated complex (IP). No coimmunoprecipitation was detected in control immunoblots for actin. The black lines on the HA-TCAFI blots indicate the removal of intervening lanes for presentation purposes. (C-F) TCAF1/2to-TRPM8 binding was assessed by measuring FRET with TM FLIM in HEK293 cells after a 24-h transfection. The TCSPC approach was chosen to achieve a good spatial resolution, which would allow discriminating TRPM8-ER localization. (C) An example of concomitant expression of TRPM8-mTurquoise2 (cyan) and TCAF1-SYFP2 (yellow). (D and E) Representative FRET-FLIM images for TRPM8-mTurquoise alone and for TRPM8-mTurquoise + TCAF 1-SYFP2, respectively. Grayscale-coded fluorescence images of the donor of FRET (left images in D and E; fluorescence intensity [FI] is given in arbitrary units [a.u.]) were analyzed by the phasor plot method (Phasor) to compute FLIM images $\left(\tau_{\text {mean }}\right)$ showing the mean lifetime (ns; right images of D and E). The outlines define the regions of interest for which mean lifetime of the donor of fluorescence was calculated. Bars, $10 \mathrm{\mu m}$. (F) Chart representing the mean lifetime of TRPM8-mTurquoise2 alone, coexpressed with the negative control SYFP2, or with TCAF1-SYFP2 or TCAF2-SYFP2. FRET efficiency (EFRE) is shown on the top of the chart. Values are presented as means \pm SD (error bars). ${ }^{* *}, \mathrm{P}<0.001$ 

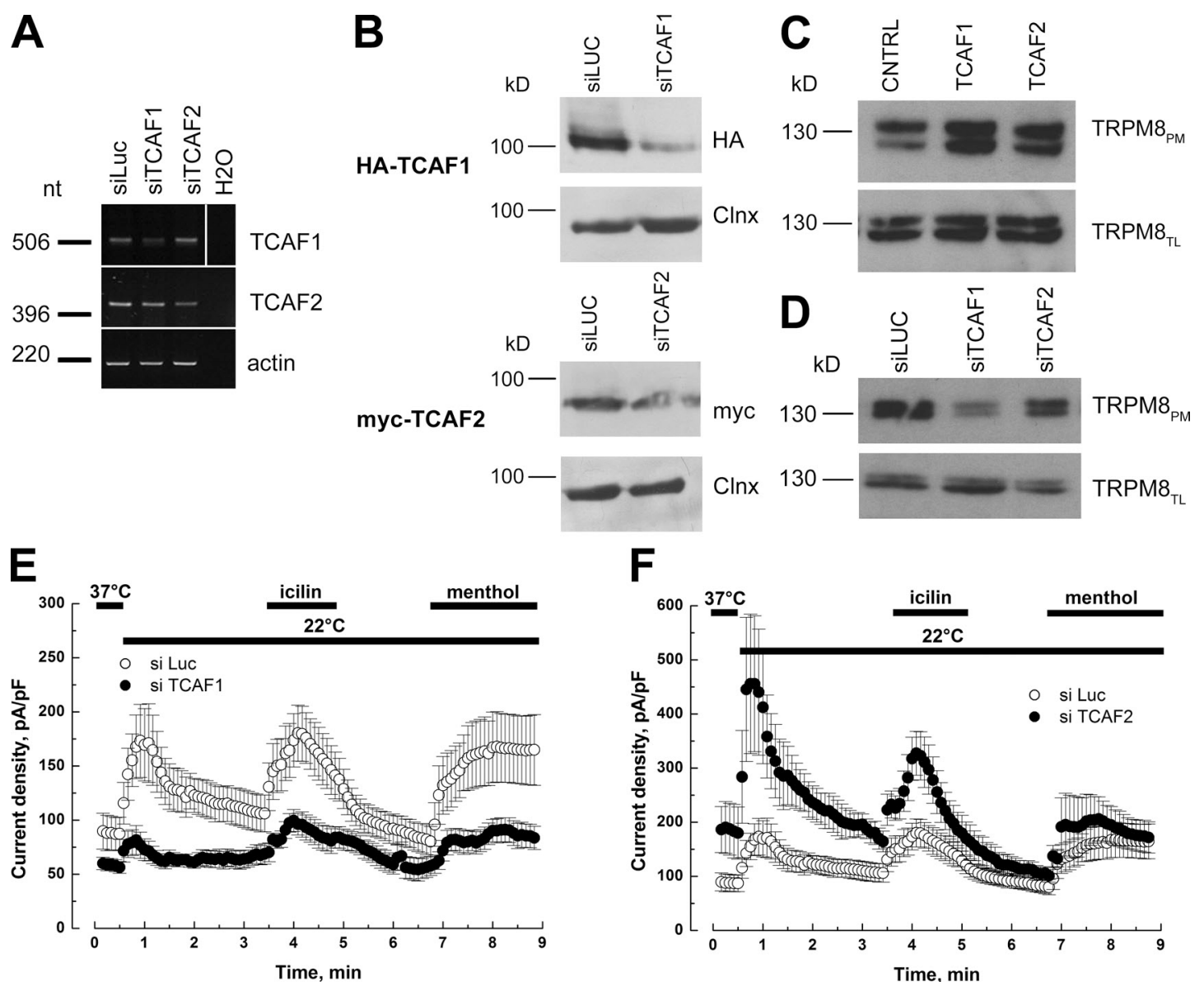

$\mathbf{F}$
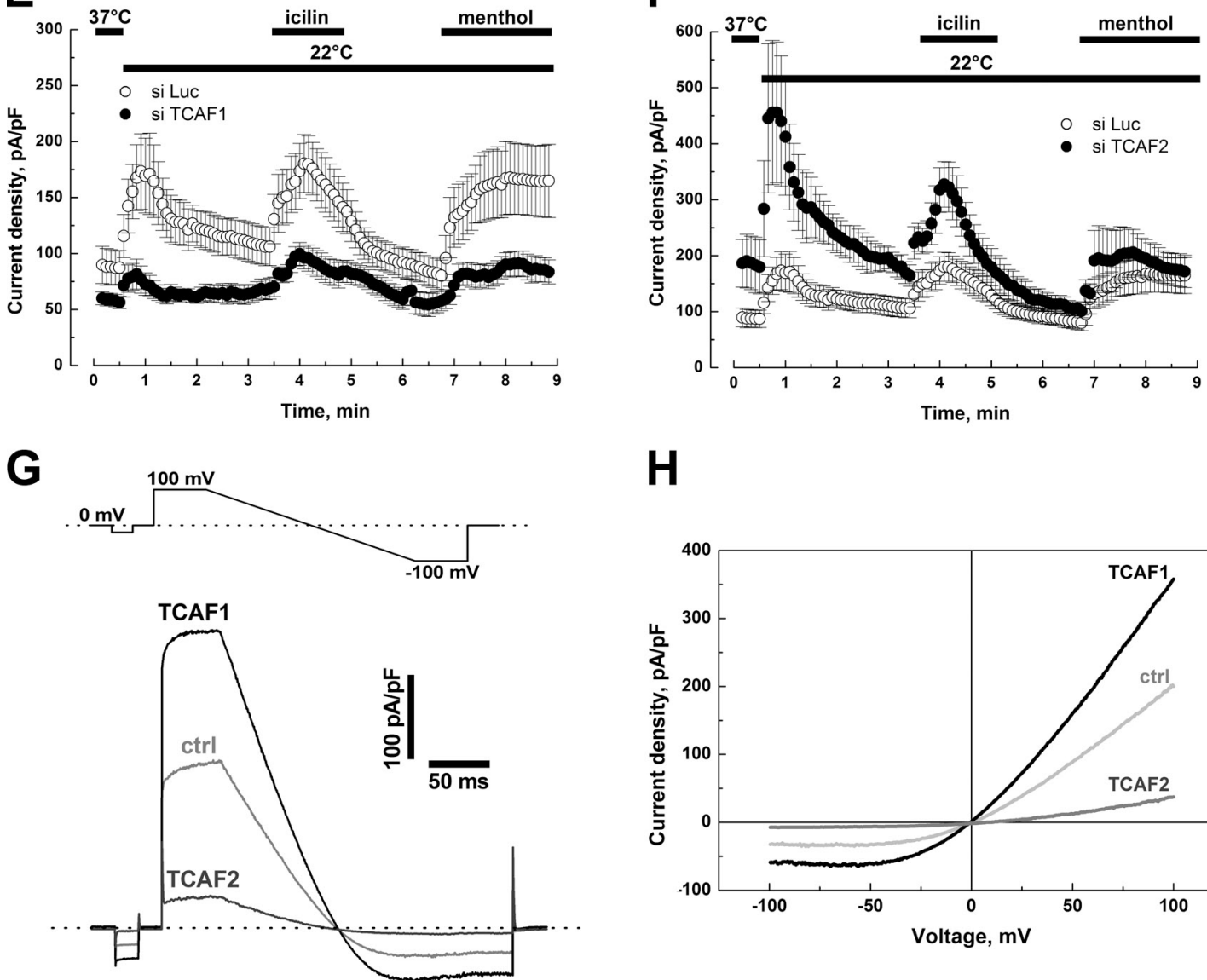

H

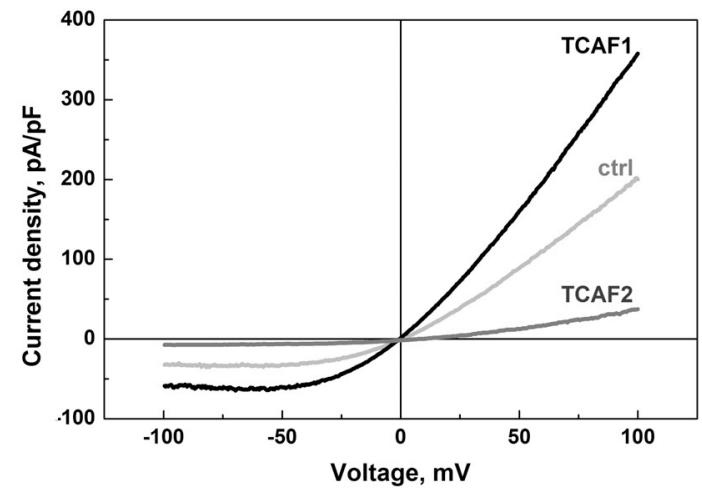

Figure 4. TCAF1 and TCAF2 proteins have opposing effects on TRPM8 activity. (A) Reverse-transcription PCR showing the specific decrease of TCAF1 (top) and TCAF2 (bottom) bands after cell transfection with $100 \mathrm{nM}$ of the respective siRNAs. Actin was used to normalize relative expression, and siRNA to luciferase was used as a negative silencing control (siluc). The white line on the TCAFl gel indicates the removal of intervening lanes for presentation purposes. (B) Western blot analysis confirming the siRNA effect on HA-TCAF1- (top) and myc-TCAF2-transfected cells (bottom). Calnexin (Clnx) was used as a loading control. (C and D) Cell surface biotinylation analysis of TRPM8-transfected cells cotransfected with the empty vector (CTRL), TCAF1, or TCAF2 (C), or co-treated with siluc, siTCAF1, or siTCAF2 (D). TRPM8 expression was analyzed by immunoblotting the plasma membrane fraction (TRPM8 $8_{\text {PM }}$ ) or total cell lysates (TRPM8 ${ }_{T \mathrm{TL}}$. Shown is the mean time course of cold- $\left(22^{\circ} \mathrm{C}\right)$, icilin- $(10 \mu \mathrm{M})$, and menthol-activated $(500 \mu \mathrm{M})$ ITRPM8 $_{\text {in }} \mathrm{LNCaP}$ cells transiently transfected with TRPM8 and treated with siluc (open circles), siTCAF1 (E), or siTCAF2 (F; closed circles). Values are expressed as means \pm SEM (error bars). (G) Single traces of menthol-evoked currents recorded in a representative LNCaP cell (out of five different cells per condition) transfected with TRPM8 and either an empty vector (ctrl), TCAF1, or TCAF2. Stimulation protocol is presented in the top panel. The corresponding IV relationships are presented in H.

at both the mRNA (Fig. 4 A) and protein levels, as seen after transfection with vectors expressing tagged proteins (Fig. 4 B). We then examined the role of the TCAFs in TRPM8 trafficking using biotin labeling. Cell-surface biotinylation experiments showed that both TCAFs enhanced channel expression in the biotinylated fraction when compared with cotransfection with 
an empty vector (Fig. 4 C), whereas siRNA to TCAF1 significantly decreased channel abundance on the plasma membrane compared with control siRNAs (siLuc; Fig. 4 D).

In terms of channel activity, TCAF1 silencing in these cells at $37^{\circ} \mathrm{C}$ induced a decrease in basal TRPM8 activity from $88.2 \pm 15.5$ to $58.9 \pm 5.3 \mathrm{pA} / \mathrm{pF}$ (Fig. $4 \mathrm{E}$ ). A similar inhibitory effect was observed on $\mathrm{I}_{\mathrm{TRPM} 8}$ currents evoked by cold, icilin, and menthol, which decreased from $158.1 \pm 73.7,111.6 \pm 38.5$, and $54.9 \pm 16.4 \mathrm{pA} / \mathrm{pF}$ in control cells $(n=12)$ to $22.8 \pm 13.3,40.8 \pm$ 10.1 , and $32.3 \pm 11.1 \mathrm{pA} / \mathrm{pF}$, respectively, in cells transfected with TCAF1 siRNA ( $\operatorname{siTCAF1;~} n=8$ ). In contrast, TCAF2 silencing led to an increase in basal $\mathrm{I}_{\text {TRPM8 }}$ amplitude from $88.2 \pm$ 15.5 to $187.4 \pm 47.9 \mathrm{pA} / \mathrm{pF}$ (Fig. $4 \mathrm{~F}$ ), whereas responses to cold, icilin, and menthol were increased from 158.1 \pm 73.7 , $111.6 \pm 38.5$, and $54.9 \pm 16.4 \mathrm{pA} / \mathrm{pF}$ in control cells $(n=12)$ to $341.3 \pm 131.9,164.2 \pm 42.3$, and $115.7 \pm 62.2 \mathrm{pA} / \mathrm{pF}$, respectively, in cells treated with TCAF2 siRNA (siTCAF2; $n=4)$. A histogram summarizing these results at both +100 and $-100 \mathrm{mV}$ is presented in Fig. S2 C, and shows similar effects of partner proteins silencing at both potentials. The overexpression of TCAF1 and TCAF2 had an opposite effect to that of the siRNAs, confirming the activating role of TCAF1 and the inhibitory role of TCAF2 on TRPM8 activity ( $n=5$; Fig. 4 , $\mathrm{G}$ and $\mathrm{H}$; and Fig. S2 D). These results clearly show that TCAF1 and -2 can modulate TRPM8 basal activity, therefore suggesting a potential role of this interaction in controlling calcium homeostasis. Moreover, TCAF1 and -2 effects on TRPM8 activity were equally observed for all tested potentials, thus precluding the existence of a voltage-dependent component to these interactions (Fig. $4 \mathrm{H}$ ).

The C-terminal tail of TCAF1 plays a critical role in TAPME regulation

TCAF1 and -2 both bind to TRPM8 and augment its targeting to the plasma membrane, while having different effects on channel activity. We therefore searched the protein sequences of TCAF1 and TCAF2 for domains that could explain this disparity. A low homology with the PI3K domain was predicted using the Conserved Domains software tool from NCBI on the C-terminal tail of TCAF1. Interestingly this domain is missing from the TCAF2 sequence, as shown in the diagram in Fig. 5 B.

To validate this putative PI3K domain in TCAF1 and assess its role in TRPM8 regulation, we first used a pharmacological approach, namely, a commonly used PI3K inhibitor wortmannin, at $1 \mu \mathrm{M}$. As shown in Fig. $5 \mathrm{~A}$, pretreatment with wortmannin resulted in a massive decrease in $\mathrm{I}_{\mathrm{TRPM} 8}$ amplitude under resting conditions as well as during exposure to cold, icilin, or menthol.

Second, we generated a truncated version of TCAF1, which lacks the C-terminal tail that contains the PI3K homology domain $\left(\mathrm{TCAF}_{\triangle \mathrm{PI} K \mathrm{~K}}\right)$ and resembles TCAF2. The direct interaction of TCAF1 $1_{\triangle \mathrm{PI} 3 \mathrm{~K}}$ with TRPM8 cytosolic tails was examined by GST pull-down. In vitro-translated $\left[{ }^{35} \mathrm{~S}\right]$ methioninelabeled TCAF1 and TCAF1 $1_{\triangle \mathrm{PI} 3 \mathrm{~K}}$ both strongly interacted with the TRPM8 N-terminal tail (GST-M8N) and to a lesser extent with the TRPM8 C-terminal tail (GST-M8C; Fig. 5 B). The functionality of $\mathrm{TCAF}_{\triangle \mathrm{PI} 3 \mathrm{~K}}$ was then assessed by $\mathrm{Ca}^{2+}$ imaging and patch-clamp experiments. Strikingly, the $\mathrm{Ca}^{2+}$ response to icilin application was very different between control, TCAF1transfected, and $\mathrm{TCAF} 1_{\triangle \mathrm{PI} 3 \mathrm{~K}}$-transfected cells: $270.2 \pm 52.5 \mathrm{nM}$, 1,375.1 $\pm 174.3 \mathrm{nM}$, and $692.6 \pm 178.3 \mathrm{nM}$ (Fig. $5 \mathrm{C}$ ). These results show a dramatic halving of TCAF1 function when its $\mathrm{PI} 3 \mathrm{~K}$ homology domain is removed, proving the importance of this domain in the mediation of TCAF1's effect on TRPM8. To assess the functional role of the TCAF1 PI3K domain on TRPM8 activity, the effect of pretreatment with $1 \mu \mathrm{M}$ wortmannin was tested on cells transfected with either wild-type TCAF1 or $\mathrm{TCAF} 1_{\triangle \mathrm{PI} 3 \mathrm{~K}}$. While TCAF1-transfected cells revealed strong sensitivity to wortmannin, the TRPM8-mediated current in $\mathrm{TCAF}_{\triangle \mathrm{P} 33 \mathrm{~K}}$-transfected cells was wortmannin insensitive (Fig. 5, $\mathrm{D}$ and E). Currents elicited by cold, icilin, and menthol were, respectively, 435.2 $\pm 76.8,254.7 \pm 42.7$, and $275.3 \pm 52.2 \mathrm{pA} / \mathrm{pF}$ in control $(n=4)$, and 78.5 $\pm 22.7,76.9 \pm 16.2$, and $57.1 \pm 11.8$ $\mathrm{pA} / \mathrm{pF}$ in wortmannin-treated TCAF1-transfected cells $(n=5)$; and $142.7 \pm 25.9,172.7 \pm 29.9$, and $130 \pm 23.4 \mathrm{pA} / \mathrm{pF}$ in control $(n=4)$, and $188.7 \pm 70.8,191.6 \pm 80.1$, and $135.6 \pm 34.5 \mathrm{pA} / \mathrm{pF}$ in wortmannin-treated TCAF $1_{\Delta \mathrm{PI} 3 \mathrm{~K}}$-transfected cells $(n=6)$.

We then examined the effect of this domain on TRPM8 trafficking to the plasma membrane. Cotransfection of TRPM8 with TCAF1 or TCAF $1_{\triangle \mathrm{PI} 3 \mathrm{~K}}$ followed by cell-surface biotinylation showed that both TCAF1 and its truncated form enhanced channel expression in the biotinylated fraction compared with cotransfection with the empty vector (Fig. 5 F).

TCAF1 and TCAF2 exert opposing

regulatory effects on endogenous

TRPMB activity

To analyze whether TCAF1 and TCAF2 are involved in the regulation of native TRPM8, we examined how the level of TCAF1 or TCAF2 expression would affect menthol-induced $\left[\mathrm{Ca}^{2+}\right]_{\mathrm{i}}$ responses in $\mathrm{LNCaP}$ cells, which naturally express TRPM8 (Valero et al., 2011, 2012). We first confirmed TRPM8 expression and activity in these cells by using siRNAs targeting the channel (Fig. S2, E and F). Next, we compared $\left[\mathrm{Ca}^{2+}\right]_{i}$ responses to $200 \mu \mathrm{M}$ menthol in fluo-4-loaded control LNCaP cells, LNCaP cells overexpressing either TCAF1 or TCAF2, and LNCaP cells pretreated with either control siRNA (siLuc), TCAF1 siRNA, or TCAF2 siRNA (Fig. 6). The siRNA experiments were also performed in human epithelial prostate cells, Ep156T (Fig. S3). Our results revealed that both the amplitude of the response and its temporal profile depended on the level of TCAF1 and TCAF2 expression. In control (Fig. $6 \mathrm{~A}$ ) and TCAF1-overexpressing (Fig. 6 B) LNCaP cells, as well as in LNCaP (Fig. 6 E) and Ep156T (Fig. S3 A) cells pretreated with siLuc or siTCAF2 (Fig. $6 \mathrm{G}$ and Fig. S3 C), menthol triggered a high-amplitude $\left[\mathrm{Ca}^{2+}\right]_{\mathrm{i}}$ transient. The magnitude of this oscillatory response was significantly reduced in cells overexpressing TCAF2 (Fig. 6 C) and was increased after pretreatment with siTCAF2 (Fig. $6 \mathrm{G}$ and Fig. S3 C). In LNCaP cells overexpressing TCAF1, an initial phase of the menthol-induced response was followed by several long-period $\left[\mathrm{Ca}^{2+}\right]_{\mathrm{i}}$ oscillations of smaller amplitude (Fig. $6 \mathrm{~B}$ ), whereas pretreatment with siTCAF1 virtually abolished all the response in both LNCaP (Fig. 6 F) and Ep156T (Fig. S3 B). As the temporal pattern of the $\left[\mathrm{Ca}^{2+}\right]_{\mathrm{i}}$ response to TRPM8 activation is complex, to quantify the effects of TCAF overexpression 
A

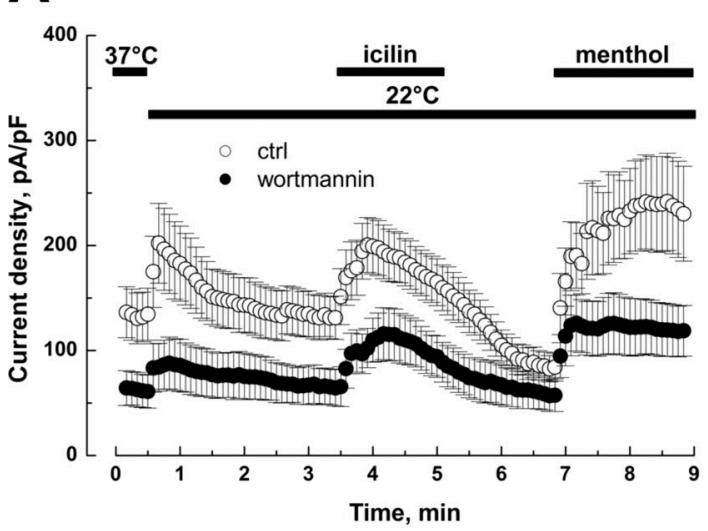

C

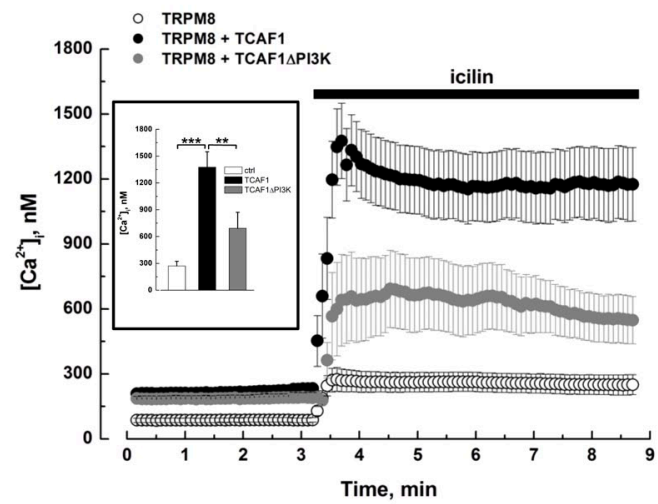

$\mathbf{E}$

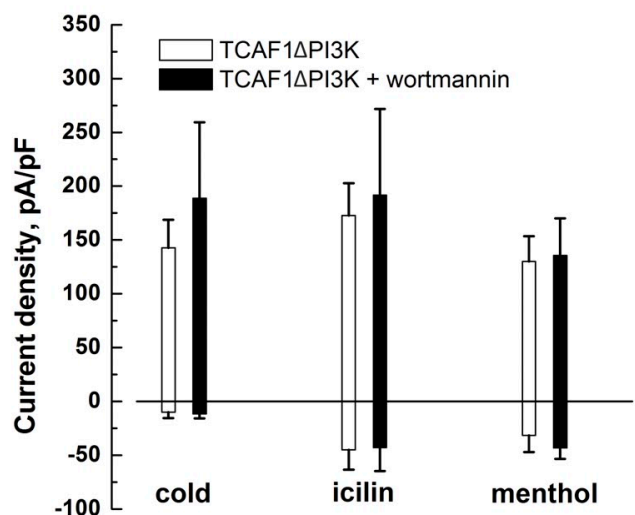

B
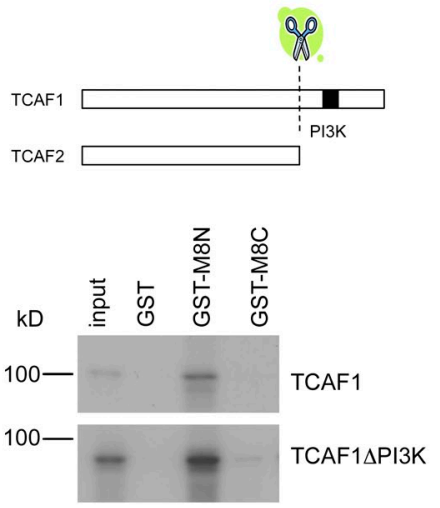

D

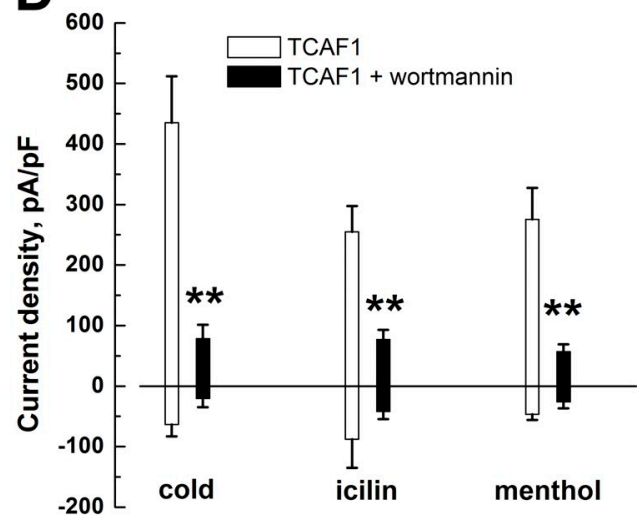

$\mathbf{F}$

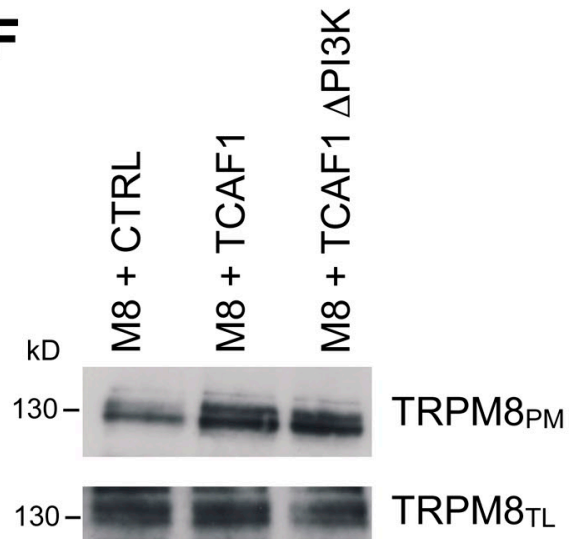

Figure 5. TCAF 1 exhibits a PI3K homology domain that is critical for the TCAF 1 modulation of TRPM 8 activity. (A) Mean time course of cold- $\left(22^{\circ} \mathrm{C}\right)$, icilin$(10 \mu \mathrm{M})$, and menthol-activated $(500 \mu \mathrm{M}) \mathrm{I}_{\text {TRPM8 }}$ in $\mathrm{LNCaP}$ cells pretreated (closed circles) or not (ctrl, open circles) for 15 min with $1 \mu \mathrm{M}$ wortmannin. For pretreated cells, experiments were performed in the continuous presence of wortmannin at the same concentration. Currents were monitored at $+100 \mathrm{mV}$, and results are presented as means \pm SEM (error bars). (B) GST pull-down assay between $\left[{ }^{35}\right.$ S]methionine-labeled TCAF 1 or TCAF $1_{\triangle P I 3 K}$ protein and GST or GST fused to the TRPM8 N-terminal tail (GST-M8N) or C-terminal tail (GST-M8C). A schematic representation of TCAF1 and TCAF2 protein sequences and the putative PI3K site is shown. (C) Time course of mean intracellular $\mathrm{Ca}^{2+}$ concentration in LNCaP cells transfected with TRPM8 and an empty vector (ctrl, open circles), wild-type TCAF 1 (TCAF 1, black closed circles), or a truncated TCAF 1 lacking the PI3K domain (TCAF1 $1_{\triangle P I 3 K}$, gray closed circles). Cells were loaded with Fura 2-AM, exposed to $10 \mu \mathrm{M}$ icilin, and variations in $\left[\mathrm{Ca}^{2+}\right]$ i were monitored using an imaging system. Results are presented as means \pm SEM (error bars). (inset) Histogram summarizing calcium imaging results (**, $\mathrm{P}<0.01$; ${ }^{* *}, \mathrm{P}<0.001$ ). (D and E) Histograms presenting mean cold$\left(22^{\circ} \mathrm{C}\right)$, icilin- $(10 \mu \mathrm{M})$, and menthol-activated $(500 \mu \mathrm{M}) \mathrm{I}_{\text {TRPM8 }}$ in $\mathrm{LNCaP}$ cells transiently transfected with TRPM8 and wild-type TCAF 1 (D) or TCAF $1_{\triangle P 13 K}$ $(E)$, and then treated (black columns) or not (white columns) with $1 \mu \mathrm{M}$ wortmannin. Results at +100 and $-100 \mathrm{mV}$ are presented as means \pm SEM (error bars; ${ }^{*}, \mathrm{P}<0.01$ ). (F) Cell surface biotinylation analysis of cells cotransfected with TRPM8 and the empty vector (CTRL), TCAF1, or TCAF1 $1_{\triangle P 13 K}$. TRPM8 expression was analyzed by immunoblotting the plasma membrane fraction (TRPM $8_{P M}$ ) or total cell lysates (TRPM8 $8_{T}$ ).

and siRNAs, we compared the fluo-4 signal during the first 18 min after menthol application in control LNCaP cells with that in $\mathrm{LNCaP}$ cells overexpressing TCAF1 or TCAF2 (Fig. 6 D), and the signal in LNCaP (Fig. $6 \mathrm{H}$ ) and Ep156T cells (Fig. S3 D) pretreated with siLuc with that pretreated with either siTCAF1 or siTCAF2. Menthol-induced $\left[\mathrm{Ca}^{2+}\right]_{\mathrm{i}}$ responses were directly correlated with changes in TCAF1 expression but inversely correlated with changes in TCAF2 expression, which indicates 


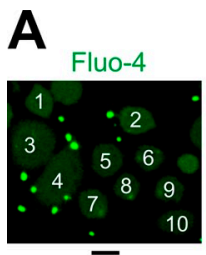

\section{Control}

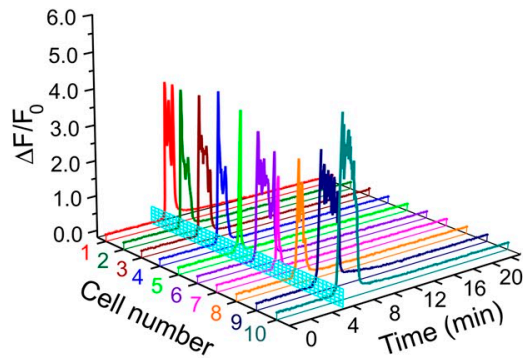

$0 \mathrm{~min} 2 \mathrm{~min} 4 \mathrm{~min} 6 \mathrm{~min} 8 \mathrm{~min} 10 \mathrm{~min} 12 \mathrm{~min} 14 \mathrm{~min} 16 \mathrm{~min} 18 \mathrm{~min}$

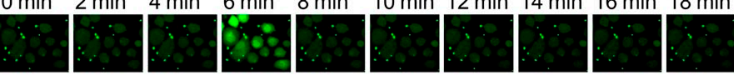

C

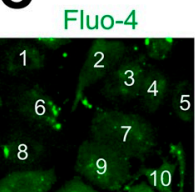

$2 \overline{\mu \mathrm{m}}$

TCAF2 overexpression

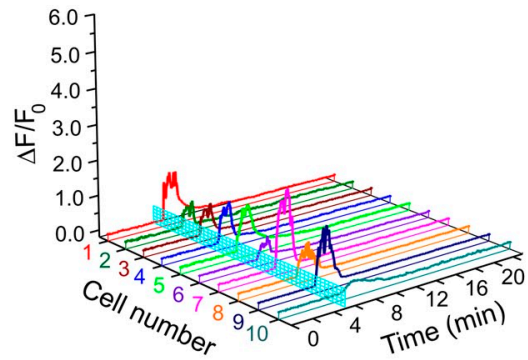

$0 \min 2 \min 4 \mathrm{~min} 6 \mathrm{~min} 8 \mathrm{~min} 10 \mathrm{~min} 12 \mathrm{~min} 14 \mathrm{~min} 16 \mathrm{~min} 18 \mathrm{~min}$

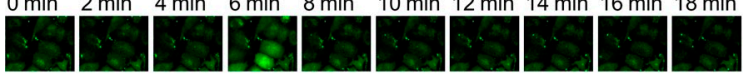

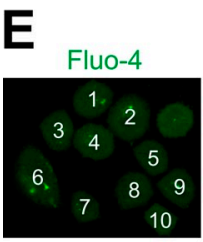

$20 \overline{\mu m}$

\section{siluc}

$\stackrel{4}{\longleftarrow}^{4} 3.0$

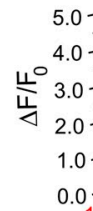

0.0

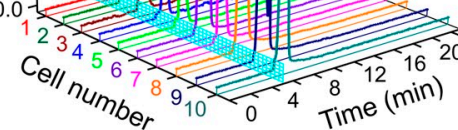

$0 \min 2 \mathrm{~min} 4 \mathrm{~min} \quad 6 \mathrm{~min} 8 \mathrm{~min} 10 \mathrm{~min} 12 \mathrm{~min} 14 \mathrm{~min} 16 \mathrm{~min} 18 \mathrm{~min}$

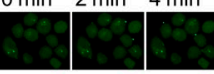

G

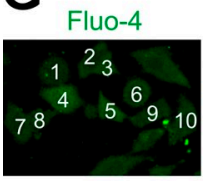

$20 \overline{\mu m}$

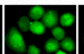

siTCAF2

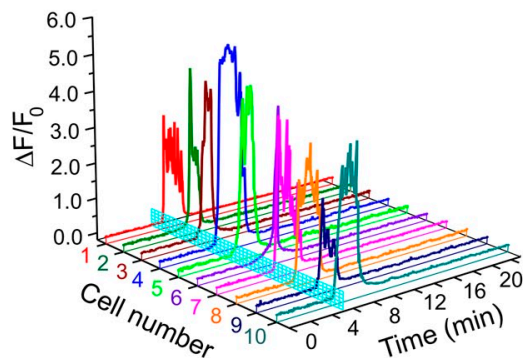

$0 \min 2 \mathrm{~min} 4 \mathrm{~min} \quad 6 \mathrm{~min} 8 \mathrm{~min} 10 \mathrm{~min} 12 \mathrm{~min} 14 \mathrm{~min} 16 \mathrm{~min} 18 \mathrm{~min}$

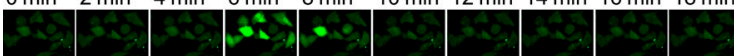

B TCAF1 overexpression
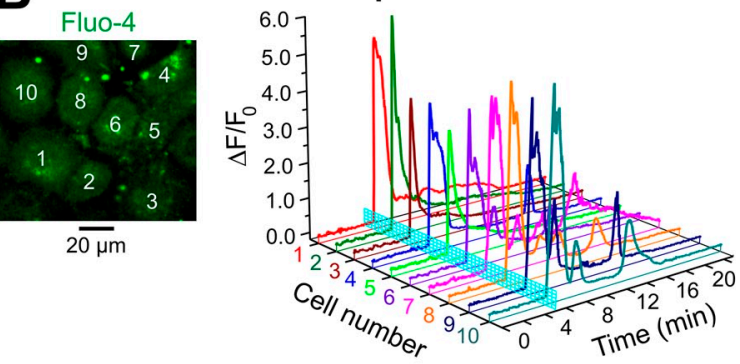

$0 \min 2 \min 4 \min 6 \min 8 \min 10 \min 12 \min 14 \min 16 \mathrm{~min} 18 \mathrm{~min}$
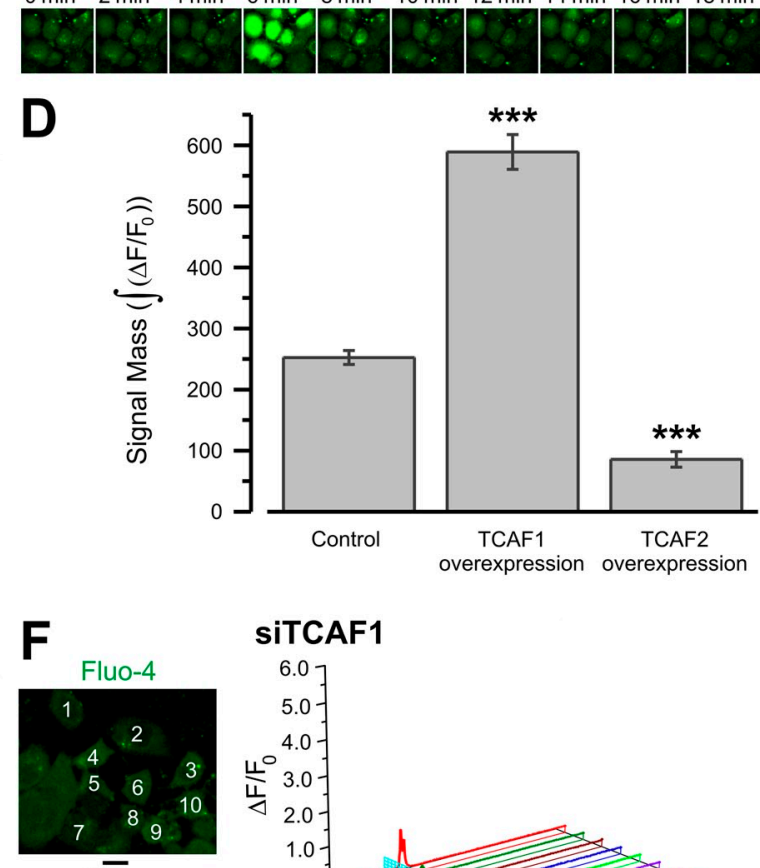

SITCAF1

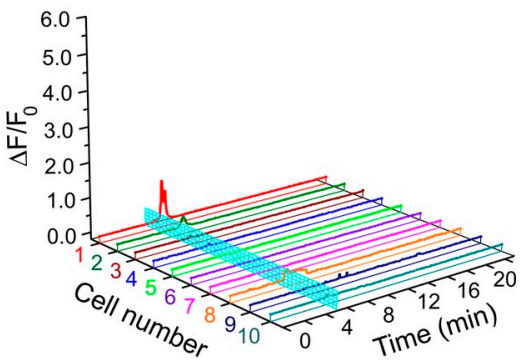

$0 \min 2 \min 4 \mathrm{~min} \quad 6 \mathrm{~min} \quad 8 \mathrm{~min} 10 \mathrm{~min} 12 \mathrm{~min} 14 \mathrm{~min} 16 \mathrm{~min} 18 \mathrm{~min}$

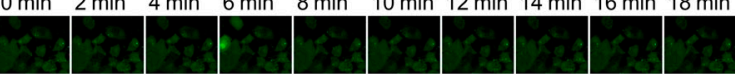

H

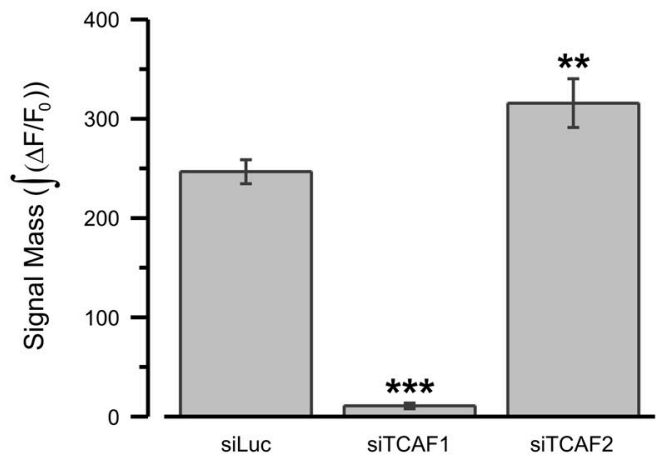

Figure 6. The menthol-induced response of endogenous TRPM8 is modulated by TCAF1 and TCAF2. (A-G) Changes of $\left[C a^{2+}\right]_{i}$ in response to the activation of TRPM8 with $200 \mu \mathrm{M}$ menthol were monitored using an $\mathrm{x}-\mathrm{y}$ time-series imaging of fluo-4 fluorescence in control LNCaP cells (A), LNCaP cells overexpressing TCAF1 (B) or TCAF2 (C), and LNCaP cells pretreated with siluc (E), siTCAF1 (F), or siTCAF2 (G). Images were acquired at 0.6 Hz from confocal optical slices $<4 \mathrm{\mu m}$. The fluorescence intensity $(\mathrm{F})$ was normalized to the averaged fluorescence intensity before menthol application ( $\left.\mathrm{F}_{0}\right)$. Relative changes in fluorescence intensity $\left(\Delta F / F_{0}\right)$, averaged within each of 10 cells denoted by the numbers on the images (left), are plotted over time. Menthol application is depicted on the 3D plots by vertical cyan bars. The galleries below the plots demonstrate the images of fluo- 4 fluorescence captured at times indicated above the images. Bar diagram plots compare masses of the fluo- 4 signal, $\int\left(\Delta F / F_{0}\right)$, during the first 18 min after menthol application $(D)$ in $L N C a P$ cells overexpressing TCAF1 $(n=48)$ or TCAF2 $(n=51)$ versus control LNCaP cells $(n=62)$, and in LNCaP cells $(\mathrm{H})$ pretreated with siTCAFl ( $n=56)$ or siTCAF2 $(n=42)$ versus $\mathrm{LNCaP}$ cells pretreated with siluc $(n=52)$. Values are expressed as means \pm SEM (error bars). ${ }^{*} * *, P<0.001 ; * *, P<0.01$. 
that TRPM8 channel opening is facilitated by TCAF1 and suppressed by TCAF2.

\section{TCAF1 binding introduces new kinetic} states to TRPMB single channel activity Next, we checked for any potential effect of TCAF1/TCAF2 on TRPM8 activity at the single channel level. These experiments were performed in HEK 293 cells expressing TRPM8 under the control of a tetracycline-inducible promoter (HEK-293 ${ }_{\mathrm{M} 8 \mathrm{i}}$; Thebault et al., 2005) in order to limit the contamination of our recordings by the activity of other channels. Control HEK$293_{\text {M8i }}$ cells as well as cells transfected with TCAF1 or TCAF2 plasmids were subjected to a short tetracycline induction as described. Then, TRPM8 activity was measured in cell-attached configuration by first recording activity at room temperature followed by the application of $100 \mu \mathrm{M}$ menthol (see Fig. S4 for sample traces). While comparing activity in control and TCAF1-transfected cells, two types of activity became apparent (Fig. 7 A). The first type, characterized by short, separate openings, was most common to control cells (19 control and 4 TCAF1-bound traces), whereas the second type exhibited the clustering of openings without any apparent increase in opening duration and was prevalent in TCAF1-transfected cells (5 control and 29 TCAF1-bound traces). In contrast, cells transfected with TCAF2 and induced according to an identical protocol exhibited virtually no TRPM8 activity (only 4 out of 31 traces exhibited TRPM8 opening), leading us to conclude that TCAF2 silences the TRPM8 channel (unpublished data).

To further study how TCAF1 binding modifies TRPM8 gating properties, the acquired traces were scrutinized for the appearance of multiple conductance levels, and those containing single-channel activity (four control and three TCAF1-bound) were individually analyzed, as described previously (Qin and Li, 2004; Fernández et al., 2011). Fig. 7 (B-D) summarizes dwell-time distributions, kinetic rates, and energy landscapes representing typical control and TCAF1-bound TRPM8 activity at room temperature and after stimulation by menthol. Interestingly, stimulation of TRPM8 activity by menthol only led to changes in the energy of the closed states, correspondingly increasing the frequency of channel openings while preserving the overall model. However, the effect of TCAF1 was qualitatively different. Although the analysis of control activity showed that the gating of TRPM8 alone could be reliably described by a relatively simple model, containing three closed and one open kinetic states (the 3c1o model; two upper panels on Fig. 7, C and D), this was not the case for the TCAF1-bound activity, suitable representation of which required a more complex model with four closed and two open states (the 4c20 model; two lower panels on Fig. 7, C and D). Fig. S5 compares the fits of the TRPM8 activity by the 4c2o and 3c1o kinetic models. Analysis of the activity of TRPM8 alone (Fig. S5, A and C) shows that both models yield identical log likelihood with additional states of the 4c2o model exhibiting virtually zero occupancy, which validates the simpler $3 \mathrm{c} 10$ model. On the contrary, analysis of the activity of TRPM8 interacting with TCAF1 (Fig. S5, B and D) shows significantly larger changes in log likelihood as well as a nontrivial occupancy of the additional states in the $4 \mathrm{c} 2 \mathrm{o}$ model, emphasizing the significance of these additional kinetic states in activity of TRPM8. In other words, the binding of TCAF1 to the TRPM8 channel introduces new kinetic states that are necessary for a satisfactory description of TRPM8 gating, which implies a direct binding of TCAF1 to TRPM8.

\section{TCAF1 but not TCAF2 shows expression patterns similar to TRPMB during carcinogenesis, and slows down cell migration}

Given the fact that TRPM8 is a marker for prostate cancer, we investigated by qPCR whether the expression of its interacting proteins, TCAF1 and TCAF2, was also associated with prostate cancer development. We initially studied TRPM8, TCAF1, and TCAF2 expression in healthy and cancerous human prostate resection samples. Patients were included in the study when both tumoral and nontumoral (healthy) tissue could be obtained from the same individual. TRPM8 and TCAF1 expression were significantly increased in cancerous samples when compared with healthy ones (10 and 5 times, respectively; $n=7-10$ for each condition, $\mathrm{P}<0.05$ ), whereas no difference was observed for the TCAF2 transcript (Fig. 8 A).

We then assessed the variation in expression of these transcripts between localized prostate cancer and metastasis to the bone marrow of patients previously subjected to androgen ablation therapy. qPCR analysis showed a clear decrease in both TRPM8 and TCAF1 expression in metastatic samples in comparison with localized prostate cancer ( $n=7-10$ for each condition, $\mathrm{P}<0.01)$. TCAF2 expression remained unchanged, as before (Fig. 8 B).

To verify that the similar expression patterns of TRPM8 and TCAF1 during carcinogenesis were also important at the functional level, we investigated the role of TCAF1 in prostate cell migration by performing time-lapse microscopy experiments on either PC3 or LNCaP prostate cancer cells (Fig. 9).

TRPM8 overexpression significantly decreases the cell migration speed, and this effect is exacerbated in the presence of icilin stimulation (Fig. 9, A and B), in accordance with our previous results on wound healing and transwell assays (Gkika et al., 2010). Moreover, TCAF1 overexpression significantly decreased the cell migration speed (Fig. 9, A and B) even in the absence of TRPM8 (Fig. 9 B). However, when overexpressed together with TRPM8, we observed a further significant decrease in the speed, which indicates that the TCAF1 effect is, at least partially, mediated by TRPM8 (Fig. 9, B and C). To test whether the inhibition of cell migration was due to the PI3K domain of TCAF1, we performed cell migration assay in cells overexpressing TCAF1 $1_{\triangle \mathrm{PI} 3 \mathrm{~K}}$ (Fig. 9, A and C). We indeed observed a significant increase in the migration speed of cells transfected with $\mathrm{TCAF} 1_{\triangle \mathrm{P} I 3 \mathrm{~K}}$ versus TCAF1-transfected cells (Fig. 9, A and C); this effect is further increased in the presence of TRPM8 (Fig. 9 C). These results are in agreement with modulation of TRPM8-mediated current by PI3K domain of TCAF1 (Fig. 5, D and E). Although TCAF2 inhibits the migration speed in the absence of TRPM8, it significantly increases the speed when TRPM8 is expressed (Fig. 9 C). 
A

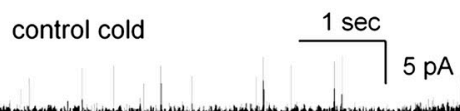

control cold + menthol

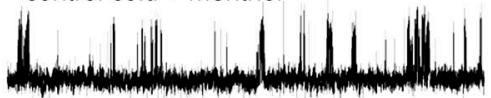

TCAF1 cold

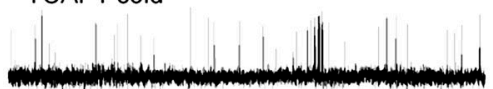

TCAF1 cold + menthol

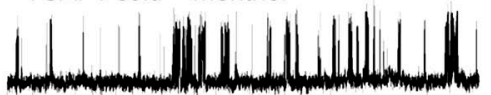

TCAF2 cold

TCAF2 cold + menthol

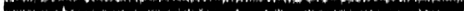

C

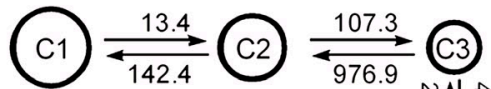

control cold

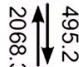

$01 \bigcirc$

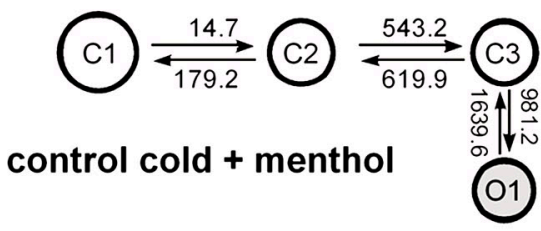
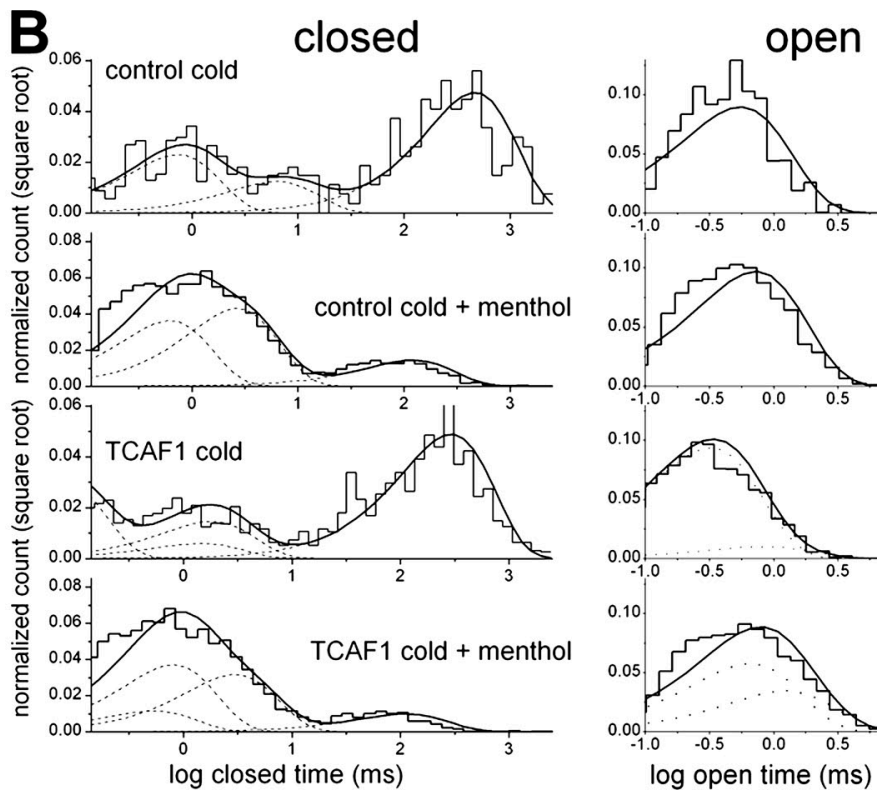

log open time (ms)
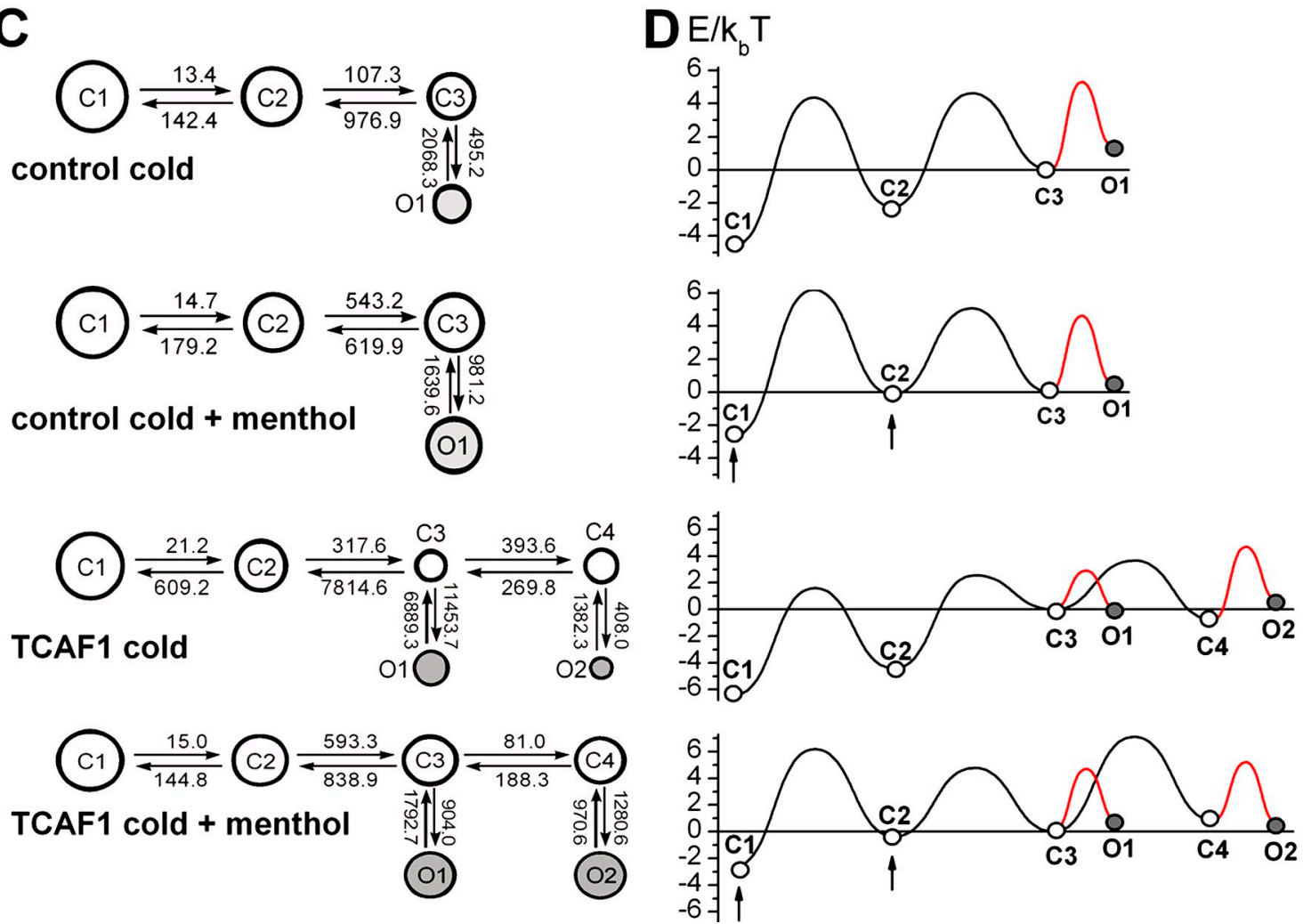

Figure 7. TCAF1 interaction with TRPM8 introduces new kinetic states. (A) Representative trace fragments of control and TCAF1-bound TRPM8 activity stimulated by cold $\left(\mathrm{T}=20^{\circ} \mathrm{C}\right.$, controlled by room thermostat) or cold + $100 \mu \mathrm{M}$ menthol, as indicated. (B) Representative distributions of closed (left) and open (Chetrite et al., 2000) dwell times in the traces of control and TCAF1-bound TRPM 8 activity stimulated as indicated. The histogram shows the distribution of dwell times. The thick continuous line represents the cumulative best fit corresponding to the kinetic model used (C) and broken lines represent individual components of the fit. (C) Kinetic models providing the best fit to the control and TCAF1-bound TRPM 8 activity. The area of each circle is proportional to the log of total time spent the corresponding state. Kinetic rates are indicated as numbers associated with the corresponding arrows. (D) Energy landscapes calculated from the corresponding kinetic models. Arrows point to significantly shifted energies in corresponding states caused by menthol stimulation. Note that contrary to the effects of different modes of TRPM8 stimulation (shifts in state energies), the interaction with TCAF1 leads to the appearance of new kinetic states.

Finally, we studied the effect of native TCAFs on cell migration with an siRNA approach. As expected, TCAF1 downregulation increases migration, which interestingly occurs by acting on the directional persistence index (Fig. 9 E) and not on the speed (Fig. 9 D). The effect on directional migration index of siTCAF1 is exacerbated in the presence of TRPM8 (Fig. 9 E). 


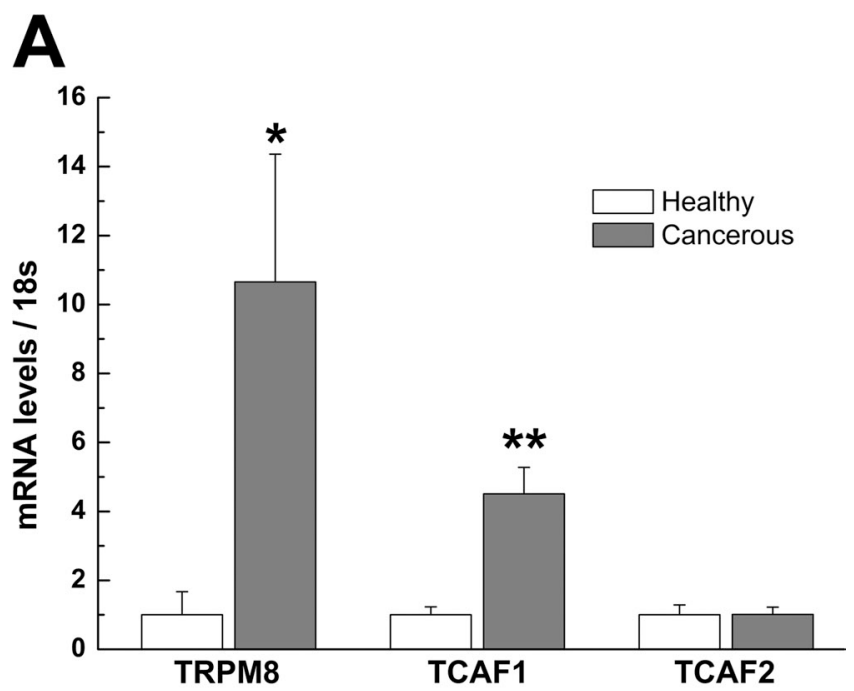

B

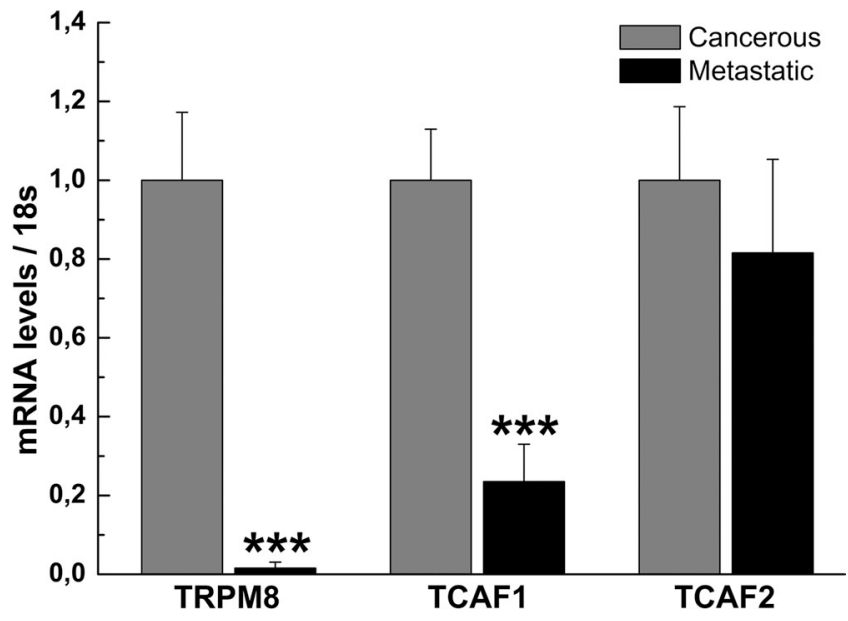

Figure 8. TCAF expression profile in prostate cancer. (A and $B$ ) Analysis of TRPM8, TCAF1, and TCAF2 mRNA expression levels by qPCR in healthy and cancerous human prostate samples (A), as well as in localized and metastatic human prostate cancer specimens (B). Values are calculated relative to $18 \mathrm{~S}$ rRNA expression and presented as means \pm SEM (error bars; $n=7-10 ; *, P<0.05 ;{ }^{*}, \mathrm{P}<0.01 ; * * *, \mathrm{P}<0.001$ ).

However, we clearly show that TCAF2 has a strong promigratory effect, which is more pronounced during TRPM8 activation, as observed by the strong inhibition of cell migration in the presence of siTCAF2 and icilin (Fig. 9 F).

\section{iscussion}

Ion channels are known to have protein partners that regulate channel localization or gating, leading to important physiological consequences. In some of the better known cases, such as the T-type calcium channels, these proteins are even acknowledged as subunits of the involved ion channel (Gerster et al., 1999). Here, we present a family of proteins, the TCAFs, which regulate the trafficking as well as gating of TRPM8, the ion channel that is known to serve as a thermal sensor in peripheral neurons and to play an important role in prostate cancer. We have demonstrated by means of cellular and molecular biology as well as electrophysiological measurements that the TCAFs interact directly with TRPM8, exerting opposing effects on channel activity. We have subsequently unraveled the molecular mechanism of TCAF action on TRPM8 activity using directed mutagenesis, biochemical assays, and single-channel analysis, demonstrating: (1) a domain responsible for their distinct channel regulation activities, (2) the effect of the TCAFs on channel plasma membrane trafficking, and (3) the qualitative effect on TRPM8 activity via the introduction of new kinetic states during gating. At the cellular level, the functional TCAF1-TRPM8 interaction leads to the inhibition of cell speed, which is also supported by the loss of expression of these proteins in human metastatic specimens. Indeed these two proteins are mainly expressed in the prostate, as demonstrated by the qPCR screening of human tissues.

Addressing the molecular mechanisms responsible for the regulation of TRPM8 activity and expression by the TCAFs, we have shown that the TCAFs interact mainly with the TRPM8 N-terminal tail. Our data imply that both proteins are critical for TRPM8 function because their silencing prevents the channel's insertion into the plasma membrane. GST pull-down experiments with in vitro translated TCAFs strongly point to the direct binding of TCAFs to TRPM8, which is further supported by the introduction of new kinetic states to TRPM8 single-channel kinetics in the presence of the TCAF1 protein, whereas TCAF2 completely silences the channel while retaining it in plasma membrane. Interestingly, this situation closely resembles the role that $\beta$ subunits play in regulating T-type calcium channels through the direct interaction of involved proteins (Gerster et al., 1999). To understand the opposing modulatory effects of TCAF1 and TCAF2, one has to look at sequence differences between the proteins, such as the loss of the C-terminal extremity in TCAF2. However, the removal of this region in TCAF1 $\left(\mathrm{TCAF} 1_{\triangle \mathrm{PI} K \mathrm{~K}}\right)$ did not completely mimic the behavior of TCAF2, and although $\mathrm{TCAF}_{\triangle \mathrm{PI} K \mathrm{~K}}$ overexpression indeed leads to a decrease in $\mathrm{I}_{\text {TRPM8 }}$ amplitude when compared with TCAF1, the extent of this decrease is significantly lower than that observed with TCAF2 overexpression. The presence in this region of a PI3K homology domain coupled with our observation that (1) a PI3K inhibitor (wortmannin) inhibits TRPM8 activity and that (2) this sensitivity to wortmannin is abolished in cells overexpressing $\mathrm{TCAF} 1_{\triangle \mathrm{PI} 3 \mathrm{~K}}$ strongly suggest that the regulatory role of the TCAFs also involves phosphorylation. In this model, both TCAF1 and TCAF2 proteins bind to TRPM8, affecting its expression on the plasma membrane. The presence of a functional PI3K homology domain, however, is required to make the channel fully active. Moreover this domain is also critical for cell motility because $\mathrm{TCAF} 1_{\triangle \mathrm{PI} 3 \mathrm{~K}}$ transfection partially reverts the inhibitory effect exerted by TCAF1. However it should be noted that because the TCAF $1_{\triangle \mathrm{PI} 3 \mathrm{~K}}$ mutant implies the deletion of TCAF1 C terminus, the loss of function may not be due only to the disruption of the PI3K-specific enzymatic activity. More experiments are thus needed to characterize the respective roles of TCAF1 functional enzymatic domain and $\mathrm{C}$ terminus.

Our phylogenetic analysis revealed that human TCAF1 and -2 are homologues of rodent TCAF3 (EAPA2) and that these three proteins form a new protein family originating from two duplication events. TCAF3 was identified in 2006 by mass 

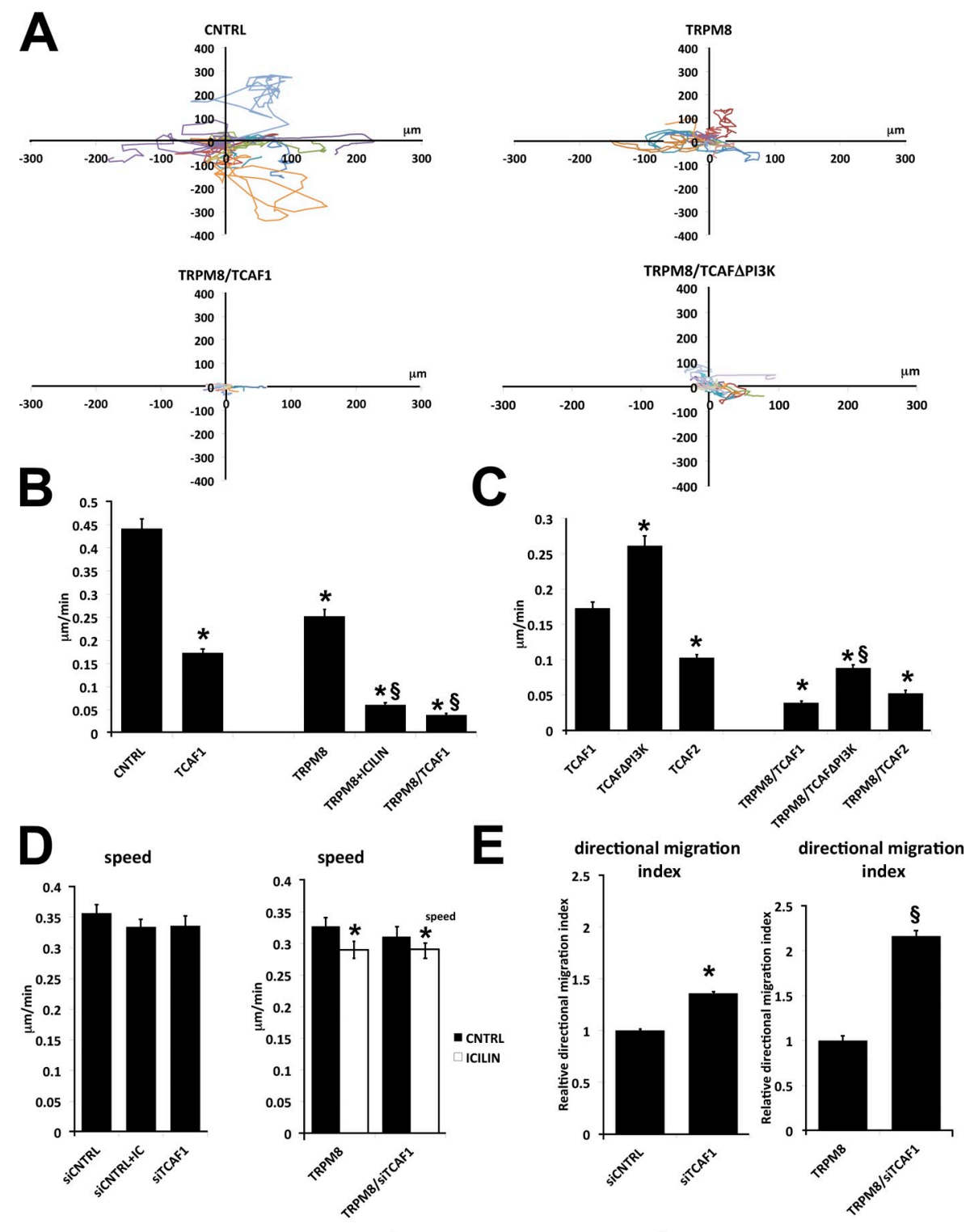

$\mathbf{F}$
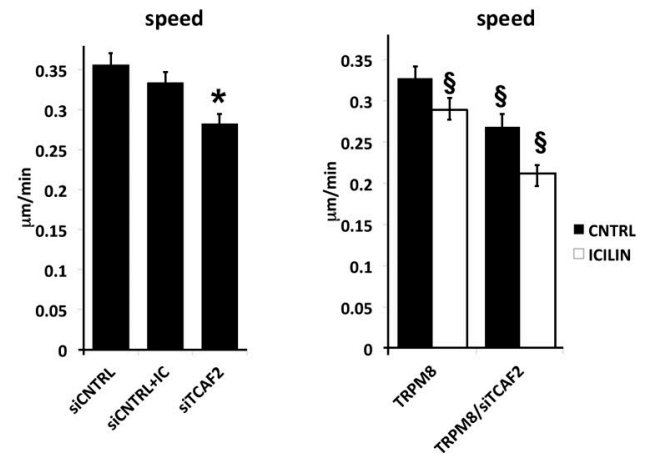

Figure 9. TCAF functional role in prostate cancer cell migration. (A) Representative migration plots of control (top left) and TRPM8overexpressing cells (top right) or TRPM8 cotransfected with wild-type TCAF1 (bottom left) or truncated TCAFI lacking the PI3K domain ( $T C A F 1_{\triangle P \mid 3 K}$, bottom right). Each line represents the migration of one cell within a 10-h period. The data shown are from a single representative experiment out of three repeats. For the experiment shown: CNTRL $n=28, \operatorname{TRPM} 8 n=58, \operatorname{TRPM} 8 / \operatorname{TCAF} 1 n=$ 69, TRPM8/TCAF1 1 PI3K $n=98$. (B and C) Bar graphs showing the quantification of cell speed in control nontransfected prostate cancer cells (CNTRL), TRPM8-overexpressing cells (TRPM8), TCAF1-overexpressing cells (TCAF1), TRPM8- and TCAF1-overexpressing cells (TRPM8/TCAF 1 ), and TRPM8 and TCAF 1 lacking the $\mathrm{PI} 3 \mathrm{~K}$ domain $\left(\mathrm{TCAF}_{\triangle \mathrm{PI} 3 \mathrm{~K}}\right)$ in the presence or absence of $10 \mu \mathrm{M}$ icilin. (D-F) Bar graphs showing the quantification of cell speed (D) and the migratory persistence index (E, calculated as indicated in the online materials) in control cells and TRPM8-overexpressing cells in which TCAF 1 or TCAF2 are down-regulated (TRPM8/siTCAF1), in the presence or absence of $10 \mu \mathrm{M}$ icilin (F). Each graph represents the quantification of pooled independent experiments (at least three experiments for each experimental condition). For each experiment, at least 60 cells were followed per condition ( ${ }^{*}, \mathrm{P}<0.05$ relative to $\mathrm{CNTRL} ; \S$ relative to TRPM8). Data are expressed as means \pm SEM (error bars). spectrometric analysis as a new prostate-specific protein regulated by androgens in mice (Fujimoto et al., 2006). At the time, the function of TCAF3 was unknown and no homologues had been identified in humans. Our discovery of the TCAF-TRPM8 interaction allows us to assign a role to this important family of proteins, often coexpressed with the TRPM8 channel. Interestingly, although TCAF1 and -2 share a common phylogenetic origin and exhibit a high degree of homology, they exert completely different regulatory effects on TRPM8. In this regard, the relative abundance of TCAFs and their competition in binding TRPM8 seems to be critical in the physiological regulation of the channel activity. This is further supported by the differences in TCAF's effect on single channel activity (the addition of one open state for TCAF1), while their binding to the channel is similar, as shown in the GST pull-down and coimmunoprecipitation assays. Moreover, the expression of TCAF1 is universally and closely 
linked to TRPM8 expression, whereas the expression of TCAF2 is mostly independent and does not exhibit large variations. Although coupling with TCAF2 completely silences TRPM8 activity, its physiological role is not clear in nonoverexpressing systems. We speculate that this might be due to the loss of the C-terminal domain in the human TCAF2. This result may be different for other mammalian TCAF2s, as this domain is still present in the genes we used for the phylogenetic analysis.

The highest expression of TRPM8 is in the prostate, where it is suggested to play a role in carcinogenesis (Thebault et al., 2005; Bidaux et al., 2007; Sabnis et al., 2008; Wondergem et al., 2008). Prostate carcinogenesis is commonly associated with major alterations in TRPM8 expression and its signaling pathway (Bavencoffe et al., 2011; Gkika and Prevarskaya, 2011; Prevarskaya et al., 2011; Shapovalov et al., 2013b). In support of this hypothesis, our data reveal that TRPM8 and TCAF1 proteins show similar expression patterns in all tissues studied. Specifically, TCAF1 expression levels increase in cancerous human prostate tissue and drop in metastatic tissue, mirroring TRPM8 levels. However, the expression levels of TCAF2 remain unchanged, which suggests the differential regulation of the two transcripts and reflects their divergence at the functional level. These observations mark TCAF1 as a good candidate for inclusion in the list of well-known prognostic markers such as TRPM8, prostein, and the prostate-specific antigen (PSA), which are also deregulated in localized primary prostate cancer, whereas their overexpression is lost again at advanced tumor stages (Schmidt et al., 2006). Moreover, the increased TRPM8 activity and expression linked to the presence of TCAF1 also affects cell migration, as shown by our time lapse video microscopy experiments, and which is in accordance with previous studies linking the overactivity of TRPM8 protein with the reduced motility of prostate cancer cells (Gkika et al., 2010). More specifically, TCAF1 exerts an antimigratory effect on prostate cancer cells by acting on the cell migration persistence, thus confirming the role of TCAF1 as a TRPM8 activator. However, the complexity of interactions described and the results of our initial GST pull-down, coimmunoprecipitations, and migration assays suggest that TCAFs are partner proteins for other ion channels, such as TRPV6 and the short isoform of TRPM2, which clearly indicates the need for further studies.

Finally, although TCAFs are strongly expressed in the prostate, we show that they are also detected in other tissues, including the brain. It is therefore possible that TCAFs are not merely limited to the role of partner proteins in prostate cells, but are also required and can be therapeutically targeted in other tissues for the stabilization of the expression and modulation of the activity of this channel. For example, TCAFs and their associated molecular pathways could be targets for pain management, according to several recent studies on TRPM8 and allodynia (Chung et al., 2011; Descoeur et al., 2011; Su et al., 2011; Kawashiri et al., 2012; Shapovalov et al., 2013a).

\section{Materials and methods}

\section{Phylogenetic analysis}

For the three genes TCAF1, TCAF2, and TCAF3, homologous sequences were downloaded from GenBank. Sequences were aligned using Seaview version 4.2.6 (Gouy et al., 2010) and manually adjusted for amino acid alignment. A data matrix containing 2,790 bp was further used for phylogenetic analyses. Any sequence shorter than half the final matrix length was removed, yielding a total of 21 sequences (NM_203396, NM_001009534, BC000609, XM_519454, NM_001132598, NM_029930, XM_342675, XM_002711950, XM_843498, NM_001099054, NM_001130025, XM_ 519453, XM_539847, NM_001101924, XM_001490518, NM_ 146174, XM_001057103, XM_002190925, NM_001094696, NM_001089327, and NM_001089327). Phylogenetic reconstructions were performed with the maximum likelihood method (ML) using PhyML 3.0 (Guindon and Gascuel, 2003), and by Bayesian analyses using MrBAYES, version 3.1.2 (Huelsenbeck and Ronquist, 2001). The best-fit model under the ML criterion was selected from the "Akaike Criterion" output of MODELTEST, version 3.7 (Posada and Crandall, 1998). For the ML analyses, node stability was estimated by 100 nonparametric bootstrap replicates (Felsenstein, 1988). For the Bayesian analyses, the dataset was divided into three partitions according to codon positions. MODELTEST version 3.7 was used to calculate the best-fit model of sequence evolution for each partition. Two runs of four Markov chains were calculated simultaneously for 4,000,000 generations with equal initial probabilities for all trees and starting with a random tree. Tree sampling frequency was each 100 generations and the consensus tree with posterior probabilities was calculated after removal of the first $25 \%$ of the total number of trees generated, corresponding to 10,000 trees. The mean standard deviation of split frequencies between the two independent runs was $<0.01$.

\section{qPCR}

qPCR of mRNA transcripts was done using MESA GREEN qPCR MasterMix Plus for the SYBR Assay (Eurogentec) on the CFX96 Real-Time PCR Detection System (Bio-Rad Laboratories) and the LightCycler System (Roche). The sequences of the primers were: for TRPM8, 5'-CGGTCATCTACGAGCCCTAC-3' and 5'-CACACACAGTGGCTTGGACT-3'; for TCAF1, 5'-TTGCCCACAGAAAATGTTGA-3' and 5'-CAGATAGGCCAGGCTGGTAG-3'; for TCAF2, 5'-ACCACGAGAATGGGAACTTG-3' and 5'-GAGCCTGTGCAGGGATATGT-3'; for $18 \mathrm{~S}$ rRNA, 5'-CAGCTTCCGGGAAACCAAAGTC-3' and 5'-AATTAAGCCGCAGGCTCCACTC-3'; for actin, 5'-TTGCTGATCCACATCTGCTG-3' and 5'-GACAGGATGCÁGAAGGAGAT-3'. $\beta$-Actin mRNA and 18S rRNA were used as endogenous controls to normalize variations in RNA extraction, the degree of RNA degradation, and the variability of reverse transcription efficiency. To quantify the results, we used the comparative threshold cycle method described by Livak and Schmittgen (2001).

For regular PCR, the following primers were used: for actin, $5^{\prime}$ CAGAGCAAGAGAGGCATCCT-3' and 5'-GTTGAAGGTCTCAAACATGATC-3'; for TCAF1, 5'-ATGGCGACTCCCTCTGCTGC-3', 5'-CCCAATCCCAGGCTTGTCCT-3', 5' -CTACTGCTGCAAGGCGTACA-3', and 5'-CCAGACCCTCGTAGCATCTT-3'.

\section{Cancer tissue sampling}

Prostate tissue samples (prostate adenocarcinoma) were obtained from 15 patients with a mean age of $62.4 \mathrm{yr}$ (ranging from 51 to 70) who underwent radical prostatectomy between January 2004 and June 2008 at the Department of Urology at the Lyon-Sud Hospital Centre. All fragments were snap-frozen and stored in liquid nitrogen until analysis. To ascertain whether the tissue was malignant or nontumoral and to confirm the Gleason score, a histological analysis of frozen sections of each sample was performed by the same pathologist before RNA extraction. Fragments fully made up of tumoral tissue were selected and classified as "tumoral," whereas samples containing no tumoral tissue were selected and classified as "nontumoral." Fragments with a mix of normal and tumoral tissue were excluded from the study. Patients were included in the study when both a "tumoral" sample and a "nontumoral" sample could be obtained from the same individual.

In addition, we used nine samples from both localized and metastatic prostate cancer obtained after informed consent from patients with localized (T2a-b) PCa for whom a prostatectomy has been scheduled, and patients with metastatic $\mathrm{PCa}(\mathrm{M} 1)$, which progressed on androgen ablation therapy, were included in a clinical research program (Protocol ID 2897) sponsored by the Hôpitaux Universitaires de Strasbourg. A total volume of $3 \mathrm{ml}$ of bone marrow were aspirated at a scintigraphic-indicated metastatic site. Microscopic observations were made from an aliquot of each bone marrow aspirate to confirm or rule out the presence of metastatic PCa cells. Total RNAs were extracted from small pieces of localized tumor by the use of the RNeasy midi kit (QIAGEN) and from bone marrow aspirates by the use of the Qiamp RNA blood kit (QIAGEN) according to the manufacturer's instructions. 
The ethics committee of the faculty of medicine and the state medical board agreed to these investigations, and informed consent was obtained from all patients.

\section{Cloning and siRNA}

The coding sequence of the N-terminal tail of TRPM8 (690 aa, S2-K691) was amplified from the hTRPM8pcDNA4 plasmid (Thebault et al., 2005) and cloned into the pGEX6p-2 vector (tac promoter) for chemically inducible, high-level expression of GST-tagged recombinant proteins (GE Healthcare) as a BamHI-Xhol fragment using the primers 5'-CGGGATCCTCCTTTCGGGCAGCCAG-3' and 5'-CCGCTCGAGTCACTTGGTGTCTCGGGAAATC-3'. Similarly, the C-terminal tail of TRPM8 (124 aa, G980-K 1 104) was cloned as a BamHI-Xhol fragment into the tac promoter pGEX6p-2 vector using the primers 5'-CGGGATCCGGCTACACGGTGGGCAC-3' and 5'-CCGCTCGAGTCACACGAGTTTGATTTTATTAGCAATC-3'. The TCAF1 and TCAF2 genes were cloned in the pGEM-T Easy vector (T7 and SP6 RNA polymerase promoter; Promega) from normal human prostate poly $(\mathrm{A})^{+} \mathrm{RNA}$ (Takara Bio Inc.) using the following primers: for TCAF1, 5'-ATGGCGACTCCCTCTGCTGC-3' and 5'-TCAGTGGGGCATCTGTGTGAGG-3'; for TCAF2, 5'-ATGGCGACCATTGCTGCTGC-3' and 5'-TCATCCCCTTCTCCCAGAATTTCTGC-3'. TCAF 1 and TCAF2 were both subcloned as EcoRI fragments into the pCMV-TnT vector (CMV promotor; Promega), TCAFl as a Xhol fragment in the PCMV-HA vector (CMV promotor; Takara Bio Inc.), and TCAF2 as an EcoRI fragment in the pCMV-myc vector (CMV promotor; Takara Bio Inc.).

For the TCAF $1_{\triangle P I 3 K}$ mutant, a stop codon was introduced into the pCMV-TNT-TCAF1 construct by the substitution C2162G using in vitro mutagenesis (QuikChange Site-directed Mutagenesis kit; Agilent Technologies). All long PCRs were performed with the High Fidelity Phusion DNA Polymerase (Finnzymes) and all constructs were verified by sequence analysis.

For the fluorescent chimera, mTurquoise 2 and SYFP2 were cloned in a home-made vector derived from pEGFP-NI (CMV promotor; Takara Bio Inc.) in which we substituted the multicloning site with a homemade counterpart that accept 5' cloning of DNA with Nhel and Agel and 3' cloning of DNA with Sac II and Not I. The sense linker sequence was: 5'-GCTAGCATTGAACCGGTGGAGTAGGCgCCGGtGGAGGAGGAGGGTtACCTGTTGTTGGAGGAGTTGTTGGAGGAGGAGTTGTTGGTGGTGTTGTTGGTGTTGGGT+ACCTGGTGGCgCCGG+GGTGTTGGCCGCGGATTATGCGGCCGC-3'. This vector was design to normalize the size and amino acid sequence of the linker between the protein of interest and the fluorescent protein. Labels given to these vectors are intuitive: X-pSYFP2$\mathrm{N}$ means that SYFP2 consists of the $\mathrm{N}$ terminal part of the chimera while $\mathrm{X}$-pmTurquoise2-C means that mTurquoise2 is located at the $\mathrm{C}$ terminus of the chimera. TRPM8-pmTurquoise2-C, TCAF 1-pSYFP2-N, TCAF 1-pSYFP2-C TCAF2-pSYFP2-N, and TCAF2-pSYFP2-C were constructed as described. T.W.J. Gadella (Swammerdam Institute for Life Sciences, van Leeuwenhoek Centre for Advanced Microscopy, University of Amsterdam, Amsterdam, Netherlands) provided the riginal pmTurquoise2-N1, pmTurquoise2-Cl, and PSYFP2-C1 vectors. Before the clone of TCAFI and -2 in the recipient vector, the Agel site was suppressed by single point mutation using in vitro mutagenesis (QuikChange Site-directed Mutagenesis kit) and checked by sequencing. Fragments were amplified by the mean of PCR with the following couples of primers: for TRPM8, 5'-GATCCCGCGGTTCCTTTCGGGCAGCCAGG-3' /5'-AGTCGCGGCCGCTCAATGGTGATGGTGATGATGACCGG-3'; for TCAF 1, 5'-GATCGCTAGCCGCCACCATGGCGACTCCCTCTGCTG-3' ' 5'-GATCACCGGTGTGGGGCATCTGTGTGA-3' and 5'-GATCCCGCGGTGCGACTCCCTCTGCTGC-3' /5'-AGTCGCGGCCGCTCAGTGGGGCATCTGTGTGAGGA-3'; for TCAF2, 5'-GATCGCTAGCCGCCACCATGGCGACCATTGCTGC-3' / 5'-GATCACCGGTTCCCCTTCTCCCAGAATTTCT-3' and 5'-GATCCCGCGGTGCGACCATTGCTGCTGCT-3' /5'-AGTCGCGGCCGCTCATCCCCTTCTCCCAGAATTTCTGC-3'. After a $0.8 \%$-agarose gel purification (Wizard SV gel and PCR Clean-Up System; Promega), PCR products and recipient vectors were digested with either Nhel + Agel or Sacll + Notl at $37^{\circ} \mathrm{C}$ overnight. After DNA purification, PCR products and vectors were ligated overnight and transformed in $\mathrm{DH} 5 \alpha$ chemo-competent bacteria (NEB). Final plasmids were extracted and sequenced before performing the experiments.

siRNAs were generated against the human sequences 5'-TTATTGGAGAGGCTTCATT-3' (siTCAF1; Eurogentec), 5'-GGCTTCCCTGGTAACATCATCCTCA-3' (siTCAF2; Invitrogen), and the luciferase 5'-CTTACGCTGAGTACTTCGA-3' (siluc; Eurogentec).

GST fusion proteins and pull-down assay

TRPM8 N- and C-terminal tail GST fusion proteins were produced and purified as per the manufacturer's instructions. In brief, BL-21 cells were transformed with the pGEX6P-2 constructs and cultured in 2XTY medium containing ampicillin $(100 \mathrm{\mu g} / \mathrm{ml})$ at $37^{\circ} \mathrm{C}$ until the $\mathrm{OD}$ reached $0.4-0.6$. IPTG was then added to a final concentration of $0.2 \mathrm{mM}$ to induce expression at $30^{\circ} \mathrm{C}$ for $4 \mathrm{~h}$. The bacteria were pelleted and resuspended in STE buffer I (10 mM Tris- $\mathrm{HCl}, 150 \mathrm{mM} \mathrm{NaCl}$, and $1 \mathrm{mM}$ EDTA, $\mathrm{pH}$ 8.0), and the cells were broken by lysozyme $(10 \mathrm{mg} / \mathrm{ml})$ incubation. After adequate sonication, the broken cells were pelleted at $13,000 \mathrm{rpm}$ for $30 \mathrm{~min}$ at $4^{\circ} \mathrm{C}$, and the supernatant was collected for purification. Because pGEX-6P-2 contains the coding region for GST, we used glutathione Sepharose 4B beads (GE Healthcare) to purify the TRPM8 N and $C$ tails.

TCAF 1, TCAF2, and TCAF $1_{\triangle P \mid 3 K}$ proteins were labeled with $\left[{ }^{35} \mathrm{~S}\right]$ methionine using a reticulocyte lysate system as per the manufacturer's instructions (Promega), added to purified GST fusion proteins, and immobilized on glutathione Sepharose $4 \mathrm{~B}$ beads in PBS containing $1 \% \mathrm{vol} / \mathrm{vol}$ Triton $X-100$. After a $2-h$ incubation at room temperature, the beads were washed extensively and bound proteins were eluted with SDS-PAGE loading buffer, separated on 10\% wt/vol SDS-PAGE gels, and visualized by autoradiography.

Preparation of prostate lysates, pull-down assay, and Fourier transform mass spectrometric analysis

The prostate was isolated from two 12-wk-old C57BL/6 male mice, which were sacrificed under $1.5 \% \mathrm{vol} / \mathrm{vol}$ isoflurane anesthesia (Nicholas Piramal Limited). The animal ethics board of the Radboud University Nijmegen approved all animal experimental procedures.

The two prostates were homogenized in homogenization buffer $\mathrm{A}$ (HbA; $20 \mathrm{mmol} /$ liter Tris/ $\mathrm{HCl}, \mathrm{pH} 7.4,5 \mathrm{mmol} /$ liter $\mathrm{MgCl}, 5 \mathrm{mmol} /$ liter $\mathrm{NaH}_{2} \mathrm{PO}_{4}, 1 \mathrm{mmol} /$ liter EDTA, $80 \mathrm{mmol} /$ liter sucrose, $1 \mathrm{mmol} /$ liter PMSF, and $5 \mathrm{~g} / \mathrm{ml}$ leupeptin and pepstatin). The protein concentration of the homogenates was determined with the Bio-Rad protein assay (Bio-Rad Laboratories). The lysates were subjected to GST pull-down with theTRPM8 $\mathrm{N}$ - and C-terminal tail GST fusion proteins while GST alone and another TRP channel (TRPV6 C-tail) were used as binding controls (as described in the GST pull-down section).

GST-precipitated proteins were subjected to Fourier transform mass spectrometry (FT-MS) in the Radboud Proteomics Centre as described previously (Vogel et al., 2007). In brief, proteins were separated on a conventional 10\% SDS-PAGE gel, then the gel was cut into eight slices for digestion by trypsin (two slices per lane, one for high molecular weight and one for low: S1 and S2 for GST, S3 and S4 for GST-TRPV6 C tail, S5 and S6 for GST-TRPM8 $\mathrm{N}$ tail, and S7 and S8 for GST-TRPM8 C tail). Peptide identification experiments were performed using a nano-HPLC 1100 nanoflow system (Agilent Technologies) connected online to a linear quadrupole ion trap-Fourier transform mass spectrometer (LTQ-FT; Thermo Fisher Scientific). Peptides and proteins were identified using the Mascot (Matrix Science) algorithm to search a local version of the NCBInr database (http://www .ncbi.nlm.nih.gov). First-ranked peptides were parsed from the Mascot database search HTML files with MSQuant (http://msquant.sourceforge.net) to generate unique first-ranked peptide lists. The full list of interacting peptides can be found in Table SI and the summary of the number of interacting peptides in Table S2.

\section{Cell culture and transfection}

HEK 293 and lymph node carcinoma of prostate (LNCaP) C4-2 cells (provided by F. Viana, Instituto de Neurociencias de Alicante, Universidad Miguel Hernandez, CSIC, Alicante, Spain; and L.A. Pardo, Max-PlanckInstitute of Experimental Medicine, Göttingen, Germany) were grown in DMEM and RPMI 1684 (Invitrogen), respectively, supplemented with 10\% fetal calf serum (Poly-Labo; Seromed), l-glutamine $(5 \mathrm{mM}$; Sigma-Aldrich), and kanamycin $(100 \mathrm{mg} / \mathrm{ml}$; Sigma-Aldrich). Human epithelial prostate cells, Ep 156T, were a gift of V. Rotter (Weizmann Institute of Science, Rehovot, Israel) and were grown in MCDB 153 modified by Biological Industries as described previously (Kogan et al., 2006).

Cells were transfected with $2 \mu \mathrm{g}$ of each construct or $50 \mathrm{nM}$ of siRNA and $0.2 \mathrm{\mu g}$ of pmax GFP using either Nucleofector (Amaxa) or FuGENE HD reagent (Roche) and HiPerFect Transfection Reagent (QIAGEN). Control experiments were performed by transfecting the empty vector or siRNA to Luciferase (siluc).

Cells were used for patch-clamp experiments $24 \mathrm{~h}$ after nucleofection and for cell surface biotinylation $48 \mathrm{~h}$ after transfection.

Immunoprecipitation and immunoblotting

Cells were cotransfected with a his-tagged hTRPM8pcDNA4 plasmid and human influenza agglutinin (HA)-tagged TCAF1 or myc-tagged TCAF2, washed twice with PBS, and incubated for $60 \mathrm{~min}$ on ice in lysis buffer $1 \%$ 
Triton X-100, 1\% sodium deoxycholate, $150 \mathrm{mM} \mathrm{NaCl}, 10 \mathrm{mM} \mathrm{NaKPO}{ }_{4}$, $\mathrm{pH} 7.2$, and anti-protease cocktail; Sigma-Aldrich). After centrifugation $\left(12,000 \mathrm{~g}\right.$ for $10 \mathrm{~min}$ at $\left.4^{\circ} \mathrm{C}\right)$ of the lysates, protein concentration was determined by the BCA assay (Thermo Fisher Scientific), and equal amount of supernatants were incubated overnight at $4{ }^{\circ} \mathrm{C}$ with mouse anti-his antibody (Invitrogen) immobilized on protein A/G PLUS agarose beads (Santa Cruz Biotechnology, Inc.). The pellet was washed three times, resuspended in SDS sample buffer, and heated at $37^{\circ} \mathrm{C}$ for $30 \mathrm{~min}$, separated on $10 \%$ $\mathrm{wt} /$ vol SDS-PAGE gels, and analyzed by immunoblotting using rabbit antiHA (1:2,000; Abcam), mouse anti-myc (1:500; Invitrogen), mouse anti-actin (1:5,000; Sigma-Aldrich), mouse anti-calnexin (1:2,000; EMD Millipore), rabbit anti-TRPM8 (1:1,500; Alomone Labs Ltd), and rabbit anti-TRPV6 (1:200; Santa-Cruz Biotechnology, Inc.) antibodies.

\section{Biotinylation}

Cells were washed twice with ice-cold PBS containing $1 \mathrm{mM} \mathrm{MgCl}$ and $0.5 \mathrm{mM} \mathrm{CaCl} 2$ (PBS-CM) $48 \mathrm{~h}$ after transfection, and surface biotinylation was performed by incubating the cells twice for $20 \mathrm{~min}$ at $4^{\circ} \mathrm{C}$ with $1 \mathrm{mg} / \mathrm{ml}$ EZ-Link Sulfo-NHS-LC-LC-Biotin (Pierce). Subsequently, cells were incubated for $5 \mathrm{~min}$ with quenching solution $\left(50 \mathrm{mM} \mathrm{NH}_{4} \mathrm{Cl}\right.$ in PBS-CM) at $4^{\circ} \mathrm{C}$ and rinsed twice with cold PBS-CM. Cells were lysed with $1 \mathrm{ml}$ of lysis buffer ( $1 \%$ Triton X-100, $1 \%$ sodium deoxycholate, $150 \mathrm{mM} \mathrm{NaCl}, 10 \mathrm{mM} \mathrm{NaKPO}{ }_{4}$, $\mathrm{pH} 7.2$, and anti-protease cocktail; Sigma-Aldrich) for $1 \mathrm{~h}$ on ice. Lysates were added to $50 \mu \mathrm{l}$ NeutrAvidin-agarose beads (Thermo Fisher Scientific). After incubation for $16 \mathrm{~h}$ at $4^{\circ} \mathrm{C}$, the beads were washed twice with PBS-CM, twice with lysis buffer, and once with $10 \mathrm{mM}$ Tris- $\mathrm{HCl}, \mathrm{pH}$ 7.5. Finally, biotinylated proteins were eluted with SDS-PAGE loading buffer, separated on $10 \% \mathrm{wt} / \mathrm{vol}$ SDS-PAGE gel, and analyzed by immunoblotting as described for the immunoprecipitation assays with rabbit anti-TRPM8 antibody (1:1,500; Alomone Labs Ltd).

\section{TD FLIM}

TD FLIM is one of the best methods to measure FRET occurrence with a good spatial resolution and independent of the concentration of proteins (Sipieter et al., 2013). As the $C$ termini of tetrameric TRPM 8 are gathered in a restricted volume, we have chosen to fuse the recently developed cyan variant (Goedhart et al., 2012), mTurquoise2, at the $C$ terminus of TRPM8. To optimize FRET occurrence, and because both the orientation and steric effect of TCAF were unknown, we generated both $\mathrm{N}$-terminal and $\mathrm{C}$-terminal SYFP2 fusion to TCAFs. Because, our preliminary experiment reported a better FRET efficiency between TRPM8-mTurquoise2 and SYFP2 fused at the $\mathrm{N}$ terminus of both TCAFs, we then focused on these pairs of FRET. For live-cell imaging, 120,000 HEK293 cells were placed on 35-mm glassbottom dishes (MatTek Corporation) and transfected for $1 \mathrm{~d}$. Before performing the experiment, dishes were filled with L-15 medium without phenol red (Life Technologies), and kept at $37^{\circ} \mathrm{C}$ using a stage incubator (Life Imaging Services). FLIM was performed with a confocal head (TCS SP5 X; Leica) with the SMD upgrade, mounted on an inverted microscope (DMI6000; Leica). A pulsed diode laser, PDL 800-B (PicoQuant GMBH), delivered $40 \mathrm{MHz}$ repetitive rate pulses at $405 \mathrm{~nm}$. The confocal pinhole was set to 1 Airy for a 0.921 - $\mu \mathrm{m}$ optical slice. Single-photon events originated from the illuminated voxel were collected through a $63 \times / 1.2 \mathrm{NA}$ water-immersion objective lens and recorded with a TCSPC detector (HydraHarp 400; PicoQuant GMBH). Fluorescence was detected through a 483/32 single band-pass filter (Semrock) on Single Photon Avalanche Photodiodes, SPAD (MPD), set up at $256 \times 256$ pixels. Arrival time of single photons was measured with SymPhoTime software (PicoQuant GMBH) while the images were taken with LAS AF software (Leica). To obtain the best resolution, a fivefold zoom factor was applied, giving a pixel size of $0.193 \mu \mathrm{m}$ and an image size of $49.21 \times 49.21 \mu \mathrm{m}$. Because the statistical determination of the distribution of single photon arrival time requires a minimum of 100 photons per pixel, 120 frames were acquired at $200 \mathrm{~Hz}$ and summed in the final image.

Because interaction dynamics rely on both the $K_{d}$ of the interaction and the spatial and temporal concomitance of the two proteins, measuring the interaction between a membrane-incorporated protein and a cytosoldiffusing protein is convoluted by strong divergence between their diffusion coefficients and their volume of mobility. Therefore, to test the ability of a free-diffusing protein to interact with TRPM8 for a period sufficient to generate a FRET signal, we concomitantly expressed a free SYFP2 protein with TRPM8-mTurquoise2.

The TD FLIM images have been analyzed with custom-made software named MAPI (IRI, USR 3078 Centre National de la Recherche Scientifique, BCF).

\section{Immunocytochemistry}

Cells were cotransfected with his-tagged hTRPM8pcDNA4 plasmid and HA-tagged TCAF 1 or myc-tagged TCAF2, and were washed two times, fixed with $4 \%$ formaldehyde-1 $\times$ PBS for $15 \mathrm{~min}$, washed three times, then permeabilized in PBS-gelatin (1.2\%) complemented with $0.01 \%$ Tween 20 and $100 \mathrm{mM}$ glycine for $30 \mathrm{~min}$ at $37^{\circ} \mathrm{C}$. Afterward, cells were incubated with primary antibodies: 1:200 goat polyclonal anti-TRPM8 antibody (Antibodies Online), rabbit anti-HA (1:100; Abcam), and mouse anti-myc (1:100; Invitrogen) in PBS-gelatin at $37^{\circ} \mathrm{C}$ for $1.5 \mathrm{~h}$. After thorough washes, the slides were treated with the corresponding secondary antibodies: donkey Rhodamine Red-X-labeled anti-goat (dilution 1:300; Jackson ImmunoResearch Laboratories, Inc.) and donkey Alexa Fluor 488-labeled anti-rabbit (dilution 1/250; Jackson ImmunoResearch Laboratories, Inc.) diluted in PBS-gelatin for $1 \mathrm{~h}$ at room temperature. The slides were then incubated with $0.3 \%$ Sudan Black in $70 \%$ ethanol in order to reduce autofluorescence, washed two times, and mounted with Mowiol. Fluorescence analysis was performed using a confocal microscope (LSM 700; Carl Zeiss, Inc.) and ImageJ analysis software.

\section{Total RNA extraction and reverse transcription}

Total RNAs were extracted from small pieces of localized tumor using the RNeasy Midi kit (QIAGEN) and from bone marrow aspirates using the QIAamp RNA Blood kit (QIAGEN) according to the manufacturer's instructions.

Total RNA from human testis, dorsal root ganglion, prostate, bladder, colon, kidney, liver, lung, smooth muscle, heart, and brain was purchased from Takara Bio Inc., and subjected to reverse transcription as described in Bidaux et al. (2007).

\section{Electrophysiology}

Macroscopic membrane ion currents were recorded at $37^{\circ} \mathrm{C}$ using the patch-clamp technique in its whole cell configuration. The currents were acquired using a PC-9 amplifier (HEKA) in the case of whole-cell measurements and an Axopatch 200B amplifier (Molecular Devices), and analyzed offline using pClamp (Molecular Devices) and Origin software (OriginLab Corporation). The extracellular solution (osmolarity $310 \mathrm{mOsmol} /$ liter) contained (in $\mathrm{mM}$ ): $150 \mathrm{NaCl}, 5 \mathrm{KCl}, 10 \mathrm{TEA}-\mathrm{Cl}, 10$ Hepes, 10 glucose, $1 \mathrm{MgCl}_{2}$, and $2 \mathrm{CaCl}_{2}, \mathrm{pH} 7.3$ (adjusted with $\mathrm{NaOH}$ ). The intracellular pipette solution (osmolarity $290 \mathrm{mOsmol} /$ liter) contained (in $\mathrm{mM}$ ): 140 $\mathrm{CsCl}, 10$ Hepes, $8 \mathrm{EGTA}, 1 \mathrm{MgCl}_{2}$, and $4 \mathrm{CaCl}_{2}\left(100 \mathrm{nM}\right.$ free $\left.\mathrm{Ca}^{2+}\right)$, $\mathrm{pH} 7.2$ (adjusted with $\mathrm{CsOH}$ ). Patch pipettes were made from borosilicate glass capillaries (WPI). The resistance of the pipettes varied between 3 and $5 \mathrm{M} \Omega$. For single-channel analysis, the extracellular and pipette solutions contained (in $\mathrm{mM}$ ): $150 \mathrm{KCl}, 5$ glucose, 10 Hepes, $1 \mathrm{CaCl}_{2}$, and $2 \mathrm{MgCl}_{2}, \mathrm{pH} 7.3$ (adjusted with $\mathrm{KOH}$ ) to bring the membrane potential close to zero and minimize junction potentials. Necessary supplements were added directly to the respective solutions at concentrations that would not significantly change the osmolarity. Changes in the external solutions were performed using a multibarrel puffing micropipette with common outflow that was positioned in close proximity to the cell under investigation. During the experiment, the cell was continuously superfused with the solution via a puffing pipette to reduce possible artifacts related to the switch from static to moving solution and vice versa.

To achieve the expression of the TRPM8 channel with a plasma membrane density of one channel per patch on average, HEK-293 ${ }_{M 8 i}$ cells were induced by $1 \mathrm{\mu g} / \mathrm{ml}$ tetracycline until the first open TRPM8 channels could be detected (typically $4 \mathrm{~h}, 20 \mathrm{~min}$ ). To prevent the overexpression of the TRPM8 channel and avoid the appearance of multiple channels, the currents were recorded within 30 min of observation of the initial TRPM8 activity. Alternatively, HEK-293 ${ }_{\mathrm{MBi}}$ cells were treated with $1 \mu \mathrm{g} / \mathrm{ml}$ tetracycline for a short duration (typically $20 \mathrm{~min}$ ). After this, cells were washed multiple times with fresh media and left overnight. Both approaches yielded identical TRPM8 currents.

The acquisition of TRPM8 activity was performed in cell-attached patches at room temperature $\left(T=20^{\circ} \mathrm{C}\right.$, controlled by a room thermostat). First, patches were subjected to a series of potentials ranging from $-100 \mathrm{mV}$ to $150 \mathrm{mV}$ to assess the presence of the TRPM 8 channel. Patches that contained TRPM8 activity were then recorded using an episodic stimulation protocol that held membrane potential at $100 \mathrm{mV}$ for $10 \mathrm{~s}$ followed by the application of $-30 \mathrm{mV}$ for $2 \mathrm{~s}$ to prevent TRPM8 activity rundown. First, activity at room temperature was recorded, followed by the application of $100 \mu \mathrm{M}$ menthol, to maximally stimulate TRPM8 channel.

Selection of traces suitable for single-channel analysis was performed by rejecting traces that at any point exhibited multiple simultaneous openings. Observing menthol-stimulated activity for at least $5 \mathrm{~min}$ 
and taking mean open and closed dwell times to be 0.6 and $19 \mathrm{~ms}$, respectively, the probability that two identical channels would never exhibit multiple conductance levels was $<\sim 10^{-210}$ (Baumgartner et al., 1997), which demonstrates the validity of this rejection criterion. Recorded activity was quantified by performing a single-channel search analysis using the Clampfit-10 program (pClamp software suit, Molecular Devices) and QuB 2.0 programs as described previously (Qin and Li, 2004; Fernández et al., 2011 ).

\section{Imaging}

Cytosolic $\mathrm{Ca}^{2+}$ concentrations were measured using the ratiometric dye Fura-2/AM (Invitrogen Ltd, UK) and quantified according to Grynkiewicz et al. (1985). Cells were loaded with $1 \mu M$ of Fura-2/AM for $30 \mathrm{~min}$ then washed and bathed in the same extracellular solution as described for whole cell recording for at least 10 min before $\mathrm{Ca}^{2+}$ measurements were done. Observations were performed at $37^{\circ} \mathrm{C}$ on an Eclipse Ti microscope using an S Fluor 20x/0.75 NA objective lens (both from Nikon). Images were collected through a Rolera $\mathrm{EM}-\mathrm{C}^{2}$ charge-coupled device (CCD) camera (Qlmaging) controlled with Metafluor software (Molecular Devices). Data were then analyzed with Origin 6.1 software (OriginLab Corporation). Unless otherwise indicated, all reagents were purchased from Sigma-Aldrich.

For the confocal $\mathrm{Ca}^{2+}$ imaging, changes in the $\left[\mathrm{Ca}^{2+}\right]_{i}$ in $\mathrm{LNCaP}$ cells were imaged using the high-affinity fluorescent $\mathrm{Ca}^{2+}$ indicator fluo-4, which was loaded by a 50 -min incubation of the cells with $5 \mu \mathrm{M}$ fluo-4 acetoxymethyl ester followed by a 60-min wash to allow time for de-esterification. Confocal $\left[\mathrm{Ca}^{2+}\right]_{i}$ imaging was performed as described previously (Povstyan et al., 2011 ; Shapovalov et al., 2013a). In brief, experimental chambers containing the cells were placed on the stage of an Axiovert 200M inverted microscope attached to an LSM 510 META laser-scanning unit (Carl Zeiss). $x$-y confocal images of fluo-4 fluorescence were acquired at $0.6 \mathrm{~Hz}$ using a Plan-Apochromat $40 \times 1.3 \mathrm{NA}$ objective lens (Carl Zeiss). Fluo-4 fluorescence was excited by the $488 \mathrm{~nm}$ line of a $500 \mathrm{~mW}$ argon ion laser (Laser-Fertigung) and was captured at wavelengths $>505 \mathrm{~nm}$. The illumination intensity was attenuated to $0.6 \%$ with an acousto-optical tunable filter (Carl Zeiss). In all experiments, the photomultiplier gain was set at 688 . To optimize signal quality, the pinhole was set to provide a confocal optical section $<4 \mu \mathrm{m}$.

\section{Time-lapse video microscopy}

Cells were seeded at low density and kept at $37^{\circ} \mathrm{C}$ under $5 \% \mathrm{CO}_{2}$ in an incubator chamber for time-lapse video recording (Okolab). Cell movements were monitored with an inverted microscope (Eclipse Ti-E; Nikon) using a $10 \times / 0.25$ NA Plan objective lens.

Images were acquired every $10 \mathrm{~min}$ for a time lapse of $10 \mathrm{~h}$ with a CCD video camera (Roper Scientific) using MetaMorph software (Universal Imaging Corp.). Image stacks were analyzed with ImageJ software and at least 60 cells per condition were manually tracked using the MtrackJ plugin. We excluded dividing cells as well as cells that exited the imaged field during the time-lapse acquisition period. The parameters of speed and migratory persistence index were considered for the data analyses. The migratory persistence index was calculated as the Euclidean distance from the starting point to the final position of the cell (i.e., the shortest distance distance) divided by the accumulated distance (total path length). This value was then normalized for the total duration of the cell track duration and the value was multiplied by the square root of the cell track duration as described previously (Messina et al., 2011).

At least six fields for each condition were analyzed in each independent experiment. At least three independent experiments were done for each experimental condition.

\section{Statistical analysis}

Values are expressed as means \pm SEM. The statistical significance of differences between groups was determined by analysis of variance (ANOVA) followed by pairwise comparison using Scheffe's method for patch-clamp recordings and an unpaired Student's $t$ test for qPCR. A nonparametric unpaired Wilcoxon-Mann-Whitney test was used as a scoring method to assess statistical significance for migration assays. Differences in means with a $\mathrm{P}<0.05$ were considered statistically significant. Statistical analyses were performed using Origin 6.1 software (OriginLab Corporation) and InStat v3.06 (GraphPad Software, Inc.) or Kaleidagraph software for migration assays (Synergy Software).

\section{Online supplemental material}

Fig. S1 shows TCAF interactions with TRPV6 and TRPM2. Fig. S2 shows the expression and functional analysis of the TRPM8-TCAFs complex.
Fig. S3 shows that menthol-induced responses in human prostate epithelial cells are modulated by TCAF 1 and TCAF2. Fig. S4 shows a sample activity of the TRPM8 channel. Fig. S5 depicts a comparison of the fit of control and TCAF1-bound TRPM8 activity to different kinetic models. Table S1 shows the full list of interacting peptides with TRPM8 channel, a summary of which can be found in Table S2. Online supplemental material is available at http://www.jcb.org/cgi/content/full/jcb.201402076/DC1.

The authors would like to thank Prof. Varda Rotter for kindly providing the human epithelial prostate cells, Ep 156T; Prof Viana and Prof. Pardo for kindly providing with prostate cell lines and input for the analysis of endogenous TRPM8 function analysis; and Prof. Theodorus W.J. Gadella for the Original pmTurquoise2- $\mathrm{N} 1$, pmTurquoise 2-C 1 , and pSYFP2-C 1 vectors.

This study was supported by grants from the French Ministère de I'Education Nationale and the Institut National de la Santé et de la Recherche Médicale. D. Gkika was supported by a long-term fellowship from the European Molecular Biology Organization (ALTF 161-2006) and the Institut National du Cancer Convention (07/3D1616/Pdoc-1 10-18/NG-NC). M. Bernardini was supported by the Vinci PhD fellowship of the Franco-Italian University (C3fr-64). D. Gordienko is supported by State Funds for Fundamental Research (F 46.2/00 1).

The authors declare no competing financial interests.

Submitted: 14 February 2014

Accepted: 1 December 2014

\section{References}

Baumgartner, W., K. Hohenthanner, G.F. Höfer, K. Groschner, and C. Romanin. 1997. Estimating the number of channels in patch-clamp recordings: application to kinetic analysis of multichannel data from voltage-operated channels. Biophys. J. 72:1143-1152. http://dx.doi.org/10.1016/S00063495(97)78763-0

Bautista, D.M., J. Siemens, J.M. Glazer, P.R. Tsuruda, A.I. Basbaum, C.L. Stucky, S.E. Jordt, and D. Julius. 2007. The menthol receptor TRPM8 is the principal detector of environmental cold. Nature. 448:204-208. http:// dx.doi.org/10.1038/nature05910

Bavencoffe, A., D. Gkika, A. Kondratskyi, B. Beck, A.S. Borowiec, G. Bidaux, J. Busserolles, A. Eschalier, Y. Shuba, R. Skryma, and N. Prevarskaya. 2010. The transient receptor potential channel TRPM8 is inhibited via the $\alpha$ 2A adrenoreceptor signaling pathway. J. Biol. Chem. 285:9410-9419. http://dx.doi.org/10.1074/jbc.M109.069377

Bavencoffe, A., A. Kondratskyi, D. Gkika, B. Mauroy, Y. Shuba, N. Prevarskaya, and R. Skryma. 2011. Complex regulation of the TRPM8 cold receptor channel: role of arachidonic acid release following M3 muscarinic receptor stimulation. J. Biol. Chem. 286:9849-9855. http://dx.doi.org/10.1074/ jbc.M110.162016

Beck, B., G. Bidaux, A. Bavencoffe, L. Lemonnier, S. Thebault, Y. Shuba, G. Barrit, R. Skryma, and N. Prevarskaya. 2007. Prospects for prostate cancer imaging and therapy using high-affinity TRPM8 activators. Cell Calcium. 41:285-294. http://dx.doi.org/10.1016/j.ceca.2006.07.002

Behrendt, H.J., T. Germann, C. Gillen, H. Hatt, and R. Jostock. 2004. Characterization of the mouse cold-menthol receptor TRPM8 and vanilloid receptor type-1 VR1 using a fluorometric imaging plate reader (FLIPR) assay. Br. J. Pharmacol. 141:737-745. http://dx.doi.org/10.1038/sj bjp. 0705652

Bidaux, G., M. Flourakis, S. Thebault, A. Zholos, B. Beck, D. Gkika, M. Roudbaraki, J.L. Bonnal, B. Mauroy, Y. Shuba, et al. 2007. Prostate cell differentiation status determines transient receptor potential melastatin member 8 channel subcellular localization and function. J. Clin. Invest. 117:1647-1657. http://dx.doi.org/10.1172/JCI30168

Bödding, M., U. Wissenbach, and V. Flockerzi. 2007. Characterisation of TRPM8 as a pharmacophore receptor. Cell Calcium. 42:618-628. http:// dx.doi.org/10.1016/j.ceca.2007.03.005

Brauchi, S., P. Orio, and R. Latorre. 2004. Clues to understanding cold sensation: thermodynamics and electrophysiological analysis of the cold receptor TRPM8. Proc. Natl. Acad. Sci. USA. 101:15494-15499. http://dx.doi.org/10 1073/pnas.0406773101

Chang, Q., S. Hoefs, A.W. van der Kemp, C.N. Topala, R.J. Bindels, and J.G. Hoenderop. 2005. The $\beta$-glucuronidase klotho hydrolyzes and activates the TRPV5 channel. Science. 310:490-493. http://dx.doi.org/10.1126/ science. 1114245

Chetrite, G.S., J. Cortes-Prieto, J.C. Philippe, F. Wright, and J.R. Pasqualini. 2000. Comparison of estrogen concentrations, estrone sulfatase and aromatase activities in normal, and in cancerous, human breast tissues. J. Steroid Biochem. Mol. Biol. 72:23-27. http://dx.doi.org/10.1016/S09600760(00)00040-6 
Chuang, H.H., W.M. Neuhausser, and D. Julius. 2004. The super-cooling agent icilin reveals a mechanism of coincidence detection by a temperaturesensitive TRP channel. Neuron. 43:859-869. http://dx.doi.org/10.1016/ j.neuron.2004.08.038

Chung, M.K., S.J. Jung, and S.B. Oh. 2011. Role of TRP channels in pain sensation. Adv. Exp. Med. Biol. 704:615-636. http://dx.doi.org/10.1007/ 978-94-007-0265-3_33

Clapham, D.E. 2003. TRP channels as cellular sensors. Nature. 426:517-524. http://dx.doi.org/10.1038/nature02196

Colburn, R.W., M.L. Lubin, D.J. Stone Jr., Y. Wang, D. Lawrence, M.R. D'Andrea, M.R. Brandt, Y. Liu, C.M. Flores, and N. Qin. 2007. Attenuated cold sensitivity in TRPM8 null mice. Neuron. 54:379-386. http://dx.doi .org/10.1016/j.neuron.2007.04.017

Descoeur, J., V. Pereira, A. Pizzoccaro, A. Francois, B. Ling, V. Maffre, B. Couette, J. Busserolles, C. Courteix, J. Noel, et al. 2011. Oxaliplatininduced cold hypersensitivity is due to remodelling of ion channel expression in nociceptors. EMBO Mol. Med. 3:266-278. http://dx.doi.org/10 $.1002 / \mathrm{emmm} .201100134$

Dhaka, A., A.N. Murray, J. Mathur, T.J. Earley, M.J. Petrus, and A. Patapoutian. 2007. TRPM8 is required for cold sensation in mice. Neuron. 54:371378. http://dx.doi.org/10.1016/j.neuron.2007.02.024

Felsenstein, J. 1988. Phylogenies from molecular sequences: inference and reliability. Annu. Rev. Genet. 22:521-565. http://dx.doi.org/10.1146/annurev ge.22.120188.002513

Fernández, J.A., R. Skryma, G. Bidaux, K.L. Magleby, C.N. Scholfield, J.G. McGeown, N. Prevarskaya, and A.V. Zholos. 2011. Voltage- and colddependent gating of single TRPM8 ion channels. J. Gen. Physiol. 137: 173-195. http://dx.doi.org/10.1085/jgp.201010498

Fujimoto, N., Y. Akimoto, T. Suzuki, S. Kitamura, and S. Ohta. 2006. Identification of prostatic-secreted proteins in mice by mass spectrometric analysis and evaluation of lobe-specific and androgen-dependent mRNA expression. J. Endocrinol. 190:793-803. http://dx.doi.org/10.1677/joe.1.06733

Gerster, U., B. Neuhuber, K. Groschner, J. Striessnig, and B.E. Flucher. 1999. Current modulation and membrane targeting of the calcium channel $\alpha 1 \mathrm{C}$ subunit are independent functions of the $\beta$ subunit. J. Physiol. 517:353368. http://dx.doi.org/10.1111/j.1469-7793.1999.0353t.x

Gkika, D., and N. Prevarskaya. 2011. TRP channels in prostate cancer: the good, the bad and the ugly? Asian J. Androl. 13:673-676. http://dx.doi.org/ 10.1038/aja.2011.18

Gkika, D., F. Mahieu, B. Nilius, J.G. Hoenderop, and R.J. Bindels. 2004. 80K-H as a new $\mathrm{Ca}^{2+}$ sensor regulating the activity of the epithelial $\mathrm{Ca}^{2+}$ channel transient receptor potential cation channel V5 (TRPV5). J. Biol. Chem. 279:26351-26357. http://dx.doi.org/10.1074/jbc.M403801200

Gkika, D., C.N. Topala, Q. Chang, N. Picard, S. Thébault, P. Houillier, J.G. Hoenderop, and R.J. Bindels. 2006a. Tissue kallikrein stimulates $\mathrm{Ca}^{\left({ }^{2+}\right)}$ reabsorption via PKC-dependent plasma membrane accumulation of TRPV5. EMBO J. 25:4707-4716. http://dx.doi.org/10.1038/sj.emboj .7601357

Gkika, D., C.N. Topala, J.G. Hoenderop, and R.J. Bindels. 2006b. The immunophilin FKBP52 inhibits the activity of the epithelial $\mathrm{Ca}^{2+}$ channel TRPV5. Am. J. Physiol. Renal Physiol. 290:F1253-F1259. http://dx.doi.org/10 .1152/ajprenal.00298.2005

Gkika, D., M. Flourakis, L. Lemonnier, and N. Prevarskaya. 2010. PSA reduces prostate cancer cell motility by stimulating TRPM8 activity and plasma membrane expression. Oncogene. 29:4611-4616. http://dx.doi.org/10.1038/ onc. 2010.210

Goedhart, J., D. von Stetten, M. Noirclerc-Savoye, M. Lelimousin, L. Joosen, M.A. Hink, L. van Weeren, T.W. Gadella Jr., and A. Royant. 2012. Structureguided evolution of cyan fluorescent proteins towards a quantum yield of 93\%. Nat. Commun. 3:751. http://dx.doi.org/10.1038/ncomms 1738

Gouy, M., S. Guindon, and O. Gascuel. 2010. SeaView version 4: A multiplatform graphical user interface for sequence alignment and phylogenetic tree building. Mol. Biol. Evol. 27:221-224. http://dx.doi.org/10.1093/ molbev/msp259

Grynkiewicz, G., M. Poenie, and R.Y. Tsien. 1985. A new generation of Ca2+ indicators with greatly improved fluorescence properties. J. Biol. Chem. 260:3440-3450.

Guindon, S., and O. Gascuel. 2003. A simple, fast, and accurate algorithm to estimate large phylogenies by maximum likelihood. Syst. Biol. 52:696-704. http://dx.doi.org/10.1080/10635150390235520

Henshall, S.M., D.E. Afar, J. Hiller, L.G. Horvath, D.I. Quinn, K.K. Rasiah, K. Gish, D. Willhite, J.G. Kench, M. Gardiner-Garden, et al. 2003. Survival analysis of genome-wide gene expression profiles of prostate cancers identifies new prognostic targets of disease relapse. Cancer Res. 63: 4196-4203.

Huelsenbeck, J.P., and F. Ronquist. 2001. MRBAYES: Bayesian inference of phylogenetic trees. Bioinformatics. 17:754-755. http://dx.doi.org/10 1093/bioinformatics/17.8.754
Kawashiri, T., N. Egashira, K. Kurobe, K. Tsutsumi, Y. Yamashita, S. Ushio, T. Yano, and R. Oishi. 2012. L type $\mathrm{Ca}^{2+}$ channel blockers prevent oxaliplatin-induced cold hyperalgesia and TRPM8 overexpression in rats. Mol. Pain. 8:7. http://dx.doi.org/10.1186/1744-8069-8-7

Kogan, I., N. Goldfinger, M. Milyavsky, M. Cohen, I. Shats, G. Dobler, H. Klocker, B. Wasylyk, M. Voller, T. Aalders, et al. 2006. hTERT-immortalized prostate epithelial and stromal-derived cells: an authentic in vitro model for differentiation and carcinogenesis. Cancer Res. 66:3531-3540. http://dx.doi .org/10.1158/0008-5472.CAN-05-2183

Köttgen, M., and G. Walz. 2005. Subcellular localization and trafficking of polycystins. Pflugers Arch. 451:286-293. http://dx.doi.org/10.1007/s00424-005-1417-3

Latorre, R., S. Brauchi, R. Madrid, and P. Orio. 2011. A cool channel in cold transduction. Physiology (Bethesda). 26:273-285. http://dx.doi.org/10 .1152 /physiol.00004.2011

Livak, K.J., and T.D. Schmittgen. 2001. Analysis of relative gene expression data using real-time quantitative PCR and the $\left.2^{(-\Delta \Delta C(\mathrm{~T})}\right)$ Method. Methods. 25:402-408. http://dx.doi.org/10.1006/meth.2001.1262

Mälkiä, A., R. Madrid, V. Meseguer, E. de la Peña, M. Valero, C. Belmonte, and F. Viana. 2007. Bidirectional shifts of TRPM8 channel gating by temperature and chemical agents modulate the cold sensitivity of mammalian thermoreceptors. J. Physiol. 581:155-174. http://dx.doi.org/10 $.1113 /$ jphysiol.2006.123059

McKemy, D.D., W.M. Neuhausser, and D. Julius. 2002. Identification of a cold receptor reveals a general role for TRP channels in thermosensation. Nature. 416:52-58. http://dx.doi.org/10.1038/nature719

Messina, A., N. Ferraris, S. Wray, G. Cagnoni, D.E. Donohue, F. Casoni, P.R. Kramer, A.A. Derijck, Y. Adolfs, A. Fasolo, et al. 2011. Dysregulation of Semaphorin7A/ $\beta 1$-integrin signaling leads to defective GnRH-1 cell migration, abnormal gonadal development and altered fertility. Hum. Mol. Genet. 20:4759-4774. http://dx.doi.org/10.1093/hmg/ddr403

Nilius, B., G. Owsianik, T. Voets, and J.A. Peters. 2007. Transient receptor potential cation channels in disease. Physiol. Rev. 87:165-217. http://dx .doi.org/10.1152/physrev.00021.2006

Peier, A.M., A. Moqrich, A.C. Hergarden, A.J. Reeve, D.A. Andersson, G.M. Story, T.J. Earley, I. Dragoni, P. McIntyre, S. Bevan, and A. Patapoutian. 2002. A TRP channel that senses cold stimuli and menthol. Cell. 108: 705-715. http://dx.doi.org/10.1016/S0092-8674(02)00652-9

Posada, D., and K.A. Crandall. 1998. MODELTEST: testing the model of DNA substitution. Bioinformatics. 14:817-818. http://dx.doi.org/10.1093/ bioinformatics/14.9.817

Povstyan, O.V., M.I. Harhun, and D.V. Gordienko. 2011. Ca2+ entry following $\mathrm{P} 2 \mathrm{X}$ receptor activation induces IP3 receptor-mediated $\mathrm{Ca}^{2+}$ release in myocytes from small renal arteries. Br. J. Pharmacol. 162:1618-1638. http://dx.doi.org/10.1111/j.1476-5381.2010.01169.x

Prevarskaya, N., R. Skryma, and Y. Shuba. 2011. Calcium in tumour metastasis: new roles for known actors. Nat. Rev. Cancer. 11:609-618. http://dx.doi .org/10.1038/nrc3105

Qin, F., and L. Li. 2004. Model-based fitting of single-channel dwell-time distributions. Biophys. J. 87:1657-1671. http://dx.doi.org/10.1529/biophysj.103.037531

Sabnis, A.S., M. Shadid, G.S. Yost, and C.A. Reilly. 2008. Human lung epithelial cells express a functional cold-sensing TRPM8 variant. Am. J. Respir. Cell Mol. Biol. 39:466-474. http://dx.doi.org/10.1165/rcmb.2007-0440OC

Schmidt, U., S. Fuessel, R. Koch, G.B. Baretton, A. Lohse, S. Tomasetti, S. Unversucht, M. Froehner, M.P. Wirth, and A. Meye. 2006. Quantitative multi-gene expression profiling of primary prostate cancer. Prostate. 66: 1521-1534. http://dx.doi.org/10.1002/pros.20490

Shapovalov, G., D. Gkika, M. Devilliers, A. Kondratskyi, D. Gordienko, J. Busserolles, A. Bokhobza, A. Eschalier, R. Skryma, and N. Prevarskaya. 2013a. Opiates modulate thermosensation by internalizing cold receptor TRPM8. Cell Reports. 4:504-515. http://dx.doi.org/10.1016/j.celrep 2013.07.002

Shapovalov, G., R. Skryma, and N. Prevarskaya. 2013b. Calcium channels and prostate cancer. Recent Patents Anticancer. Drug Discov. 8:18-26. http:// dx.doi.org/10.2174/1574892811308010018

Sinkins, W.G., M. Goel, M. Estacion, and W.P. Schilling. 2004. Association of immunophilins with mammalian TRPC channels. J. Biol. Chem. 279: 34521-34529. http://dx.doi.org/10.1074/jbc.M401156200

Sipieter, F., P. Vandame, C. Spriet, A. Leray, P. Vincent, D. Trinel, J.F. Bodart, F.B. Riquet, and L. Héliot. 2013. From FRET imaging to practical methodology for kinase activity sensing in living cells. Prog. Mol. Biol. Transl. Sci. 113:145-216. http://dx.doi.org/10.1016/B978-0-12-386932-6.00005-3

Stein, R.J., S. Santos, J. Nagatomi, Y. Hayashi, B.S. Minnery, M. Xavier, A.S. Patel, J.B. Nelson, W.J. Futrell, N. Yoshimura, et al. 2004. Cool (TRPM8) and hot (TRPV1) receptors in the bladder and male genital tract. J. Urol. 172:1175-1178. http://dx.doi.org/10.1097/01.ju.0000134880.55119.cf

Su, L., C. Wang, Y.H. Yu, Y.Y. Ren, K.L. Xie, and G.L. Wang. 2011. Role of TRPM8 in dorsal root ganglion in nerve injury-induced chronic pain. BMC Neurosci. 12:120. http://dx.doi.org/10.1186/1471-2202-12-120 
Thebault, S., L. Lemonnier, G. Bidaux, M. Flourakis, A. Bavencoffe, D. Gordienko, M. Roudbaraki, P. Delcourt, Y. Panchin, Y. Shuba, et al. 2005. Novel role of cold/menthol-sensitive transient receptor potential melastatine family member 8 (TRPM8) in the activation of store-operated channels in LNCaP human prostate cancer epithelial cells. J. Biol. Chem. 280:3942339435. http://dx.doi.org/10.1074/jbc.M503544200

Tsavaler, L., M.H. Shapero, S. Morkowski, and R. Laus. 2001. Trp-p8, a novel prostate-specific gene, is up-regulated in prostate cancer and other malignancies and shares high homology with transient receptor potential calcium channel proteins. Cancer Res. 61:3760-3769.

Valero, M., C. Morenilla-Palao, C. Belmonte, and F. Viana. 2011. Pharmacological and functional properties of TRPM8 channels in prostate tumor cells. Pflugers Arch. 461:99-114. http://dx.doi.org/10.1007/s00424-0100895-0

Valero, M.L., F. Mello de Queiroz, W. Stühmer, F. Viana, and L.A. Pardo. 2012. TRPM8 ion channels differentially modulate proliferation and cell cycle distribution of normal and cancer prostate cells. PLOS ONE. 7:e51825. http://dx.doi.org/10.1371/journal.pone.0051825

van de Graaf, S.F., J.G. Hoenderop, D. Gkika, D. Lamers, J. Prenen, U. Rescher, V. Gerke, O. Staub, B. Nilius, and R.J. Bindels. 2003. Functional expression of the epithelial $\mathrm{Ca}\left({ }^{2+}\right)$ channels (TRPV5 and TRPV6) requires association of the S100A10-annexin 2 complex. EMBO J. 22:1478-1487. http://dx.doi.org/10.1093/emboj/cdg162

van de Graaf, S.F., J.G. Hoenderop, and R.J. Bindels. 2006. Regulation of TRPV5 and TRPV6 by associated proteins. Am. J. Physiol. Renal Physiol. 290: F1295-F1302. http://dx.doi.org/10.1152/ajprenal.00443.2005

Veliz, L.A., C.A. Toro, J.P. Vivar, L.A. Arias, J. Villegas, M.A. Castro, and S. Brauchi. 2010. Near-membrane dynamics and capture of TRPM8 channels within transient confinement domains. PLOS ONE. 5:e13290. http:// dx.doi.org/10.1371/journal.pone.0013290

Voets, T., G. Droogmans, U. Wissenbach, A. Janssens, V. Flockerzi, and B. Nilius. 2004. The principle of temperature-dependent gating in cold- and heat-sensitive TRP channels. Nature. 430:748-754. http://dx.doi.org/10 1038/nature02732

Vogel, R.O., R.J. Janssen, M.A. van den Brand, C.E. Dieteren, S. Verkaart, W.J. Koopman, P.H. Willems, W. Pluk, L.P. van den Heuvel, J.A. Smeitink, and L.G. Nijtmans. 2007. Cytosolic signaling protein Ecsit also localizes to mitochondria where it interacts with chaperone NDUFAF1 and functions in complex I assembly. Genes Dev. 21:615-624. http://dx.doi .org/10.1101/gad.408407

Wondergem, R., T.W. Ecay, F. Mahieu, G. Owsianik, and B. Nilius. 2008. HGF/ SF and menthol increase human glioblastoma cell calcium and migration. Biochem. Biophys. Res. Commun. 372:210-215. http://dx.doi.org/ 10.1016/j.bbrc.2008.05.032

Yang, Z.H., X.H. Wang, H.P. Wang, and L.Q. Hu. 2009. Effects of TRPM8 on the proliferation and motility of prostate cancer PC-3 cells. Asian J. Androl. 11:157-165. http://dx.doi.org/10.1038/aja.2009.1

Yee, N.S., W. Zhou, and M. Lee. 2010. Transient receptor potential channel TRPM8 is over-expressed and required for cellular proliferation in pancreatic adenocarcinoma. Cancer Lett. 297:49-55. http://dx.doi.org/ 10.1016/j.canlet.2010.04.023

Yudin, Y., and T. Rohacs. 2012. Regulation of TRPM8 channel activity. Mol. Cell. Endocrinol. 353:68-74. http://dx.doi.org/10.1016/j.mce.2011.10.023

Zhang, L., and G.J. Barritt. 2006. TRPM8 in prostate cancer cells: a potential diagnostic and prognostic marker with a secretory function? Endocr. Relat. Cancer. 13:27-38. http://dx.doi.org/10.1677/erc.1.01093

Zhang, X., S. Mak, L. Li, A. Parra, B. Denlinger, C. Belmonte, and P.A McNaughton. 2012. Direct inhibition of the cold-activated TRPM8 ion channel by Gaq. Nat. Cell Biol. 14:851-858. http://dx.doi.org/10.1038/ ncb2529

Zhu, G., X. Wang, Z. Yang, H. Cao, Z. Meng, Y. Wang, and D. Chen. 2011 Effects of TRPM8 on the proliferation and angiogenesis of prostate cancer PC-3 cells in vivo. Oncol Lett. 2:1213-1217. 